\title{
Comparing mothers and fathers on acceptability of parent- training approaches, knowledge of behavioral principles, and parenting behaviors
}

Jennifer D. Tiano

West Virginia University

Follow this and additional works at: https://researchrepository.wvu.edu/etd

\section{Recommended Citation}

Tiano, Jennifer D., "Comparing mothers and fathers on acceptability of parent-training approaches, knowledge of behavioral principles, and parenting behaviors" (2006). Graduate Theses, Dissertations, and Problem Reports. 4342.

https://researchrepository.wvu.edu/etd/4342

This Dissertation is protected by copyright and/or related rights. It has been brought to you by the The Research Repository @ WVU with permission from the rights-holder(s). You are free to use this Dissertation in any way that is permitted by the copyright and related rights legislation that applies to your use. For other uses you must obtain permission from the rights-holder(s) directly, unless additional rights are indicated by a Creative Commons license in the record and/ or on the work itself. This Dissertation has been accepted for inclusion in WVU Graduate Theses, Dissertations, and Problem Reports collection by an authorized administrator of The Research Repository @ WVU.

For more information, please contact researchrepository@mail.wvu.edu. 
Comparing Mothers and Fathers On Acceptability of Parent-Training Approaches, Knowledge of Behavioral Principles, and Parenting Behaviors

Jennifer D. Tiano

\begin{abstract}
Dissertation submitted to the Eberly College of Arts and Sciences

at West Virginia University in partial fulfillment of the requirements

for the degree of
\end{abstract}
Doctor of Philosophy
in
Psychology

\author{
Cheryl B. McNeil, Ph.D., Chair \\ William Fremouw, Ph.D. \\ Tracy L. Morris, Ph.D. \\ Matthew Scullin, Ph.D. \\ Christina Wilson, Ph.D.
}
Department of Psychology
Morgantown, West Virginia 2006

Keywords: Treatment Acceptability, Knowledge of Behavioral Principles, Parenting, Fathers 


\begin{abstract}
Comparing Mothers and Fathers On Acceptability of Parent-Training Approaches, Knowledge of Behavioral Principles, and Parenting Behaviors
\end{abstract}

\author{
Jennifer D. Tiano
}

Although most child research is conducted with mothers as the primary source of data, results often are applied to fathers. Yet, mothers and fathers engage in different interactions with children and may have varying attitudes and knowledge of parenting. This project compared mothers and fathers on a variety of parenting measures. Participants included a community sample of 80 parents (40 mother-father pairs) and their male child between the ages of two and seven. This study evaluated potential differences between mothers and fathers on treatment acceptability, knowledge of behavioral principles, and observed parenting behaviors. Results indicated that mothers prefer response cost while fathers prefer spanking, though acceptability of spanking was low for both parents. Mothers and fathers exhibited similar knowledge of behavioral principles, but mothers utilized more positive verbalizations than fathers in parentchild interactions. Limitations and future directions are discussed. 


\section{Acknowledgements}

Several individuals should be acknowledged for their contribution to and guidance throughout this project.

First, extreme gratitude goes to Dr. Cheryl McNeil who has been an outstanding mentor to me throughout my undergraduate and graduate career. In fact, Cheryl has not only become my mentor, but my friend. I have learned so much from her about clinical work, research, mentoring, and being the best professional and mother that I can be. Cheryl has supported me through many trials and joyous moments and for this I am most grateful.

Second, I would like to thank the numerous individuals that contributed their time during the conceptualization and data collection portions of this project including Lindsey Burrell, Rebecca Grate, and Cheryl McNeil's research labs of 2005 and 2006.

Most importantly, I would like to thank my husband, Scott and my son, Ayden for the love and support they have provided me in my life. I am so grateful to Scott for fixing meals for me on late work nights, comforting me through difficult times, and sharing in my joys and successes. His pride in my accomplishments helped me to strive for greatness. Ayden has provided me with unconditional love and an outlet for relieving stress after hard days. I love you both very much. 


\section{Table of Contents}

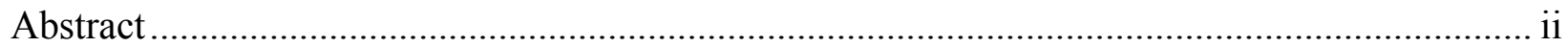

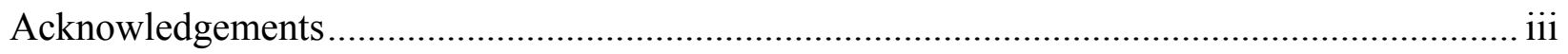

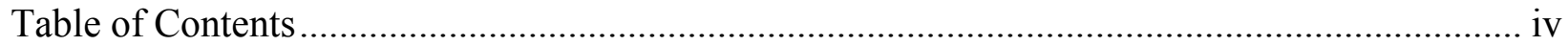

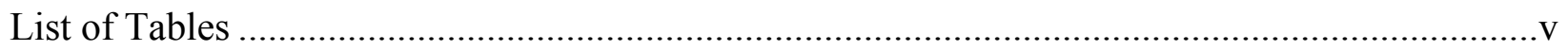

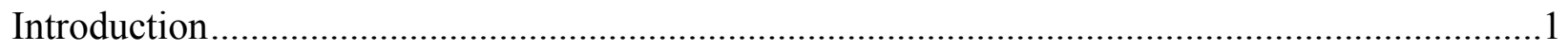

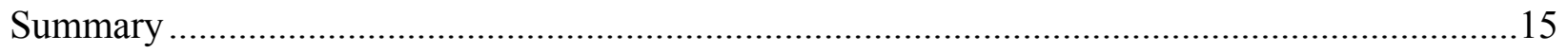

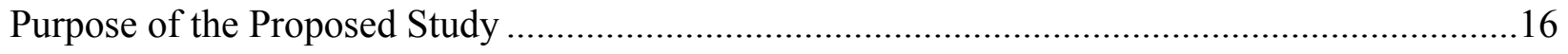

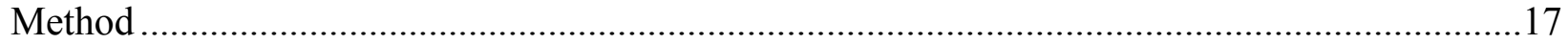

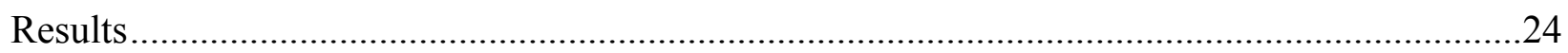

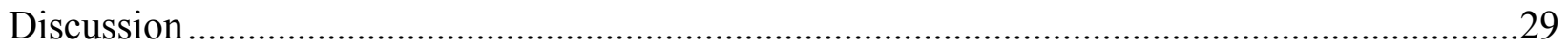

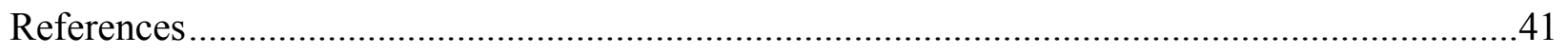

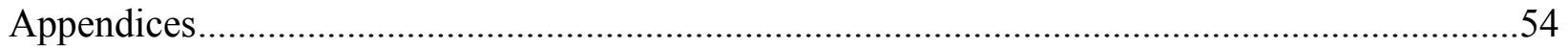

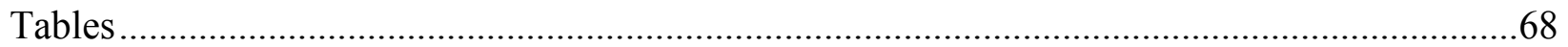




\section{List of Tables}

Table 1. Demographic Characteristics of Entire Sample.........................................................68

Table 2. Demographic Characteristics of Sample Based on Gender .....................................69

Table 3. Follow-up Paired-Samples T-tests of TEI-SF Acceptability Scores ............................70

Table 4. Follow-up Paired-Samples T-tests of Observed Behavior Composites........................71

Table 5. Intercorrelations Between Father Involvement and Paternal Variables .........................72

Table 6. Intercorrelations Between Demographic Variables and Treatment Acceptability and Knowledge of Behavioral Principles .................................................................. 73

Table 7. Intercorrelations Between Demographic Variables and Observed Behaviors.................74 
Comparing Mothers and Fathers On Acceptability of Parent-Training Approaches, Knowledge of Behavioral Principles, and Parent Behaviors

Most of the literature concerning children has been conducted with mothers. However, research has stressed the importance of fathers in child development, suggesting that fathers may provide unique contributions to their children's behaviors, apart from the influence of mothers (Lamb, 1997; Palkovitz, 1996; Parke \& Brott, 1999; Popenoe, 1999). In addition, the majority of child development theories have been derived from research with mothers and applied to work with fathers. Therefore, few, if any, paternal theories have been derived separately from work with mothers (Phares, 1992). Because mothers and fathers engage in dissimilar interactions with their children (Dickson, Walker, \& Fogel, 1997; Lamb, 1981), the theories and project designs in the child literature may not apply to research with fathers.

Data on paternal parenting behaviors also may provide an inaccurate representation of how fathers interact with their children, because most of this information about fathers has been derived via mothers' reports of paternal behavior or fathers' self-report. Behavioral observations of father-child interactions almost are nonexistent in the huge literature on parenting behaviors. The lack of objective measures of paternal behavior impedes the ability to draw conclusions about father-child interactions.

With regard to interparental agreement of child behavior problems, conflicting results have arisen in the literature. Some studies have found that mothers tend to report more behavior problems in their children than fathers (Achenbach \& Edelbrock, 1983; Calzada, Eyberg, Rich, \& Querido, 2004; Christensen, Margolin, \& Sullaway, 1992; Eisenstadt, McElreath, Eyberg, \& McNeil, 1994; Webster-Stratton, 1988), while others have found that mothers' and fathers' report of problem behaviors in their children were similar (Eyberg \& Ross, 1978; Stranger \& Lewis, 1993; Webster-Stratton). It has been suggested that mothers may report more child 
disruptive behaviors than fathers because mothers usually spend more time with their children than fathers. Thus, mothers may be more aware of behavior problems and have more opportunities to experience difficulty with children (Christensen et al.). In addition, children exhibit greater compliance for fathers than mothers and are more likely to obey their mothers when fathers are present (Calzada, Eyberg, Rich, \& Querido; Campbell, 1991; Patterson, 1980). Fathers then would experience noncompliance less often than mothers, and as a result rate their children's behaviors as more positive than mothers (Eisenstadt, McElreath, Eyberg, \& McNeil). In addition to obtaining little data from fathers, when children's maladaptive behaviors warrant intervention, few fathers actively have participated in behavioral parent training (BPT) outcome studies (Budd \& O’Brien, 1982; Coplin \& Houts, 1991; Tiano \& McNeil, 2005). From 1970 to 1981, only 3 studies (13\%) utilizing BPT included fathers (Budd \& O'Brien). This rate improved to 35 (37\%) BPT studies from 1981 to 1988 (Coplin \& Houts), but decreased to 14 studies from 1989 to 2003 (Tiano \& McNeil, 2005). This neglect of fathers is unfortunate, as this type of treatment particularly may be appealing to fathers. In most parent-training programs, behavior management skills often are learned by parents through play situations while interacting with their children (e.g., Eyberg \& Robinson, 1982; Forehand \& McMahon, 1981; WebsterStratton, 1985c). As play activities surround most father-child interactions (Lamb, 1981; Lewis, 1997; McBride \& Mills, 1993; Russell \& Russell, 1987), BPT may provide a comfortable setting for fathers to learn parenting techniques while increasing the likelihood of paternal participation in parenting programs.

Research has supported the efficacy of BPT in decreasing child externalizing behaviors (Brestan \& Eyberg, 1998; Graziano \& Diament, 1992). As research examining BPT has been conducted with children exhibiting conduct problem behaviors and their parents, parental 
satisfaction of these behavior modification techniques with parents of children exhibiting typical behaviors are unclear. In addition, it is unclear as to whether these behavioral strategies are part of the typical parents' behavioral repertoires. Because BPT is effective in decreasing problem behaviors in children, parents of children with few or minor behavior problems may benefit from the knowledge and skills targeted in BPT (e.g., consistency, understanding of behavioral theories, effective discipline strategies).

Inclusion of Fathers In Parenting Programs

Some community efforts to involve fathers in their children's lives have emerged. For example, parent education programs designed to target communication skills with their children, normal child development, and parenting skills have been conducted with fathers (e.g., Levant \& Doyle, 1983; McBride, 1990). Some research has suggested that such programs may encourage fathers to acquire a more active role with their children (McBride \& McBride, 1993). Head Start also provides programs to increase paternal involvement in the child's life. Fathers are encouraged to participate in the Head Start classroom and in recreational activities with their children. Following participation in the Head Start program, Fagan and Iglesias (1999) found changes in both child and father behaviors. More specifically, children whose fathers were highly involved in the Head Start program exhibited better mathematics skills than low-fatherinvolvement children. Highly involved fathers increased the amount of time they devoted to direct child interactions, availability to the child, and the child's education. In addition, when controlling for the effects of mother involvement, positive paternal behavior continued to be associated with positive child outcomes (e.g., less depression, higher self-esteem, less delinquency; as cited in Marsiglio, Amato, \& Day, 2000).

Including fathers in programs targeting parenting behaviors is important because fathers, 
as well as mothers, may contribute to the development of child behavior problems. In fact, many parenting programs were developed based on the assumption that poor parent-child interactions increased externalizing behaviors (Dumas, 1989; Patterson, 1982; Sanders \& Dadds, 1993). Furthermore, poor father-child relationships have been associated with future problem behaviors in adolescence (Atwood, Gold, \& Taylor, 1989), while harsh, inconsistent discipline delivered by fathers is more associated with child conduct problem behaviors than maternal use of discipline (Patterson \& Dishion, 1988).

Attempts should be made to include fathers in parenting programs a this point in time because the father's role in the family has been changing. Fathers are spending more time with their children than before. More specifically, Pleck (1997) found that in the 1990's fathers spent $43 \%$ as much time as mothers in direct interactions with their children, as compared to $17 \%$ in the 1970's. Fathers also have become more involved in childrearing activities than in previous years (Pleck; Radin, 1986). In fact, the number of stay-at-home fathers has increased $18 \%$ from $1994(\sim 155,000)$ to $2003(\sim 189,000$; U.S. Census Bureau, 2002). Additionally, mothers and fathers have indicated that both parents equally should share child responsibilities including discipline, emotional support, play, monitoring, and caregiving in addition to providing financial support to the family (Milkie, Bianchi, Mattingly, \& Robinson, 2002).

Another reason for including fathers in parenting programs is to encourage the consistent application of parent behavior. Research has shown that children receiving inconsistent discipline are at risk for developing problem behaviors (Frick, Christian, \& Wootton, 1999; Patterson, 1982; Strassberg, Dodge, Pettit, \& Bates, 1994). In fact, Webster-Stratton (1985a) found that mothers utilized parenting skills more consistently when fathers were involved in the treatment than when fathers were not involved. When fathers are involved, parents receiving 
training can utilize similar techniques and support each other in the use of the new behavior management skills (Bagner \& Eyberg, 2003a; Webster-Stratton). Furthermore, parents tend to drop out of programs less frequently and maintain treatment gains better when both parents participate in training (Bagner \& Eyberg, 2003b; Clark \& Baker, 1983; Strain, Young, \& Horowitz, 1981; Webster-Stratton). Thus, encouraging father as well as mother participation in parenting programs may be quite beneficial in obtaining positive and persistent effects for both parents and children.

One final reason for increasing father participation in parenting activities involves child outcomes from father-absent families. More specifically, six-year-old children who reported the presence of a father figure exhibited less aggressive behaviors than children with no father figure (Marshall, English, \& Stewart, 2001). In addition, children exhibiting externalizing behaviors are more likely to reside with only one parent than children exhibiting typical behaviors (Biller, 1993; Campbell, March, Pierce, Ewing, \& Szumowski, 1991; Friedemann \& Andrews, 1990; Levy-Shiff, 1982; Velez, Johnson, \& Cohen, 1989; Webster-Stratton \& Hammond, 1990). In fact, as compared to children without behavior problems, children with conduct problem behaviors are 11 times more likely to live in mother-only households (Sheline, Skipper, \& Broadhead, 1994).

In sum, most child and parenting research has been conducted with mothers, though fathers have been found to contribute to child development as well. The current investigation compared mothers and fathers of nonreferred young male children on the following characteristics: (a) acceptability of various techniques commonly used for inappropriate child behaviors, (b) knowledge of behavioral principles relating to child behavior, and (c) observation of various parenting and child behaviors exhibited during parent-child interactions. Gaining more 
information about father-child interactions and paternal parenting skills and knowledge may aid in understanding how to involve and increase participation of fathers in a variety of parenting programs (e.g., Head Start, parent education, BPT).

This paper is organized in the following manner. First, maternal and paternal acceptability of treatments with young children is discussed. Second, a review of research on knowledge of behavioral principles obtained from a variety of individuals (e.g., undergraduates, therapists) is provided. Third, a discussion of behavior observational data of mother, father, and child behaviors exhibited during dyadic interactions is provided. Fourth, results are presented. Finally, findings, limitations, and future directions are discussed.

\section{Treatment Acceptability}

It has been suggested that treatment compliance and maintenance of treatment gains are positively related to the degree of treatment acceptability (Frentz \& Kelley, 1986; Kazdin, 1980ab, 1981). Kazdin (1980a) defined treatment acceptability as potential clients' judgments about the intervention. Treatment acceptability may be expanded to include how suitable one feels the treatment is for a particular problem, whether one feels the treatment is reasonable and nonintrusive, and whether the intervention procedures are in accordance with one's preconception of treatment. To assess treatment acceptability, Kazdin developed the Treatment Evaluation Inventory (TEI; 1980a). On the TEI, parents rate the acceptability of treatments used with children by completing the 15 items. Each item is rated on a seven-point Likert scale from 1 (not acceptable at all) to 7 (very acceptable). Thus, the higher the score, the more appropriate the parent considers the treatment. This measure has been utilized in numerous assessments of acceptability of interventions for child problems (Gage \& Wilson, 2000), though very few have assessed fathers' opinions. 
The TEI was used to evaluate the treatment acceptability of medication and behavioral interventions for parents of children with and without Attention Deficit-Hyperactivity Disorder (ADHD; Gage \& Wilson, 2000). All parents (38 mothers and 22 fathers) were randomly assigned to three treatment conditions (i.e., medication, behavioral intervention, combination) and rated each intervention's acceptability. Although both mothers and fathers were assessed, results reported mother and father data together as "parent" data. Parents of children with ADHD were more accepting of medication and the combination treatment than parents of children without ADHD. Parents of children without ADHD rated the behavioral intervention as the most acceptable treatment for ADHD-type behaviors.

Mothers of children exhibiting disruptive behaviors rated the acceptability of six common strategies used for externalizing behaviors (i.e., differential attention, overcorrection, positive reinforcement, response cost, spanking, and timeout; Jones, Eyberg, Adams, \& Boggs, 1998). Mothers read a description of a child exhibiting behaviors consistent with a diagnosis of Oppositional Defiant Disorder (ODD). Following this description were six explanations of how each strategy could be used to manage the problem behaviors. Mothers rated the acceptability of the six interventions using the short form of the TEI. Results indicated that mothers considered positive reinforcement the most acceptable form of intervention for use with ODD-type behaviors. Following positive reinforcement were response cost, timeout, differential attention, overcorrection, and spanking. In fact, mothers rated spanking as significantly less acceptable than all other interventions, and spanking was the only intervention whose rating fell below the moderate acceptability range.

Mothers, fathers, and grandparents of clinic-referred children rated the acceptability of interventions for a variety of problems commonly endorsed by children seeking treatment 
(Miltenberger, Parrish, Rickert, \& Kohr, 1989). More specifically, caregivers evaluated differential reinforcement of other behaviors (DRO), response cost, timeout, and spanking as applied to noncompliance, aggression, tantrums, and hyperactivity. Additionally, caregivers rated their acceptance of a medication intervention when hyperactivity was the presenting problem. Results were not analyzed separately for the various caregivers (i.e., mothers, fathers, and grandparents). For all behavior problems assessed, caregivers were more accepting of DRO, response cost, and timeout than spanking. For hyperactivity, in particular, the medication and spanking treatments were rated significantly less acceptable than the other three strategies (i.e., DRO, response cost, and timeout).

Miller and Kelley (1992) examined both mothers' and fathers' acceptability of common interventions used with children. These parents reported no experience with behavioral treatments, and their children had never been referred for psychological evaluations or treatment. Similar to the study conducted by Jones, Eyberg, Adams, and Boggs (1998), parents (69 mothers and 69 fathers) read a story of a child exhibiting externalizing behaviors and then six different intervention vignettes to address the behaviors. The six interventions (i.e., positive reinforcement, response cost, medication, room timeout, chair timeout, and spanking) were assessed utilizing the TEI. Mothers rated the following interventions as significantly more acceptable than fathers: positive reinforcement, response cost, and room timeout. On the other hand, fathers rated spanking and medication as significantly more acceptable than mothers, though paternal ratings of these two interventions were below the moderate acceptability range. Parents did not differ on their rating of chair timeout. It should be noted that although most ratings by fathers were lower than mothers' ratings, fathers were quite accepting of all treatments except spanking and medication. 
The TEI is one of the most commonly used instruments to assess treatment acceptability, though fathers' ratings frequently are excluded from the literature. Previous literature conducted with mothers, teachers, and undergraduate students often produce a common finding: higher acceptability of positive than reductive interventions (e.g., Jones, Eyberg, Adams, \& Boggs, 1998; Kazdin, 1981; Witt \& Robbins, 1985). In comparing mothers' and fathers' acceptability, Miller and Kelley (1992) also found that both parents rate positive treatments more favorably than negative treatments, though parents differed on their ratings. However, no conclusions about the comparison of mothers and fathers on treatment acceptability can be made from this one study. More research should be conducted in this area to allow generalization of the findings. Knowledge of Behavioral Principles

As previously stated, BPT programs are efficacious treatments for child externalizing behaviors and are based on behavioral principles (e.g., positive reinforcement, punishment, contingencies; Kazdin, 1987; Serketich \& Dumas, 1996). Thus, at completion of treatment, parents receiving BPT should exhibit some understanding of behavioral principles. In a study by McLoughlin (1985), nineteen mothers read a manual of behavior management strategies (not behavioral principles) and implemented those strategies with their child's negative behaviors. Findings indicated that mothers' knowledge of behavioral principles increased as a result of utilizing behaviorally-oriented approaches. Similarly, after completion of a 5-hour child management training, parents' KBPAC scores increased from $48 \%$ to $85 \%$ (O'Dell, TarlerBenlolo, \& Flynn, 1979). In comparing group parent training and individual family therapy, Pevsner (1982) found that after treatment families receiving group therapy exhibited more knowledge of behavioral principles than individual therapy families. However, neither O'Dell et al. nor Pevsner indicated either which parent completed the KBPAC or scores for both parents. 
Thus, no research was found that reported maternal and paternal KBPAC scores separately or that evaluated behavioral principles knowledge of mothers and fathers who received BPT.

More recent research with the KBPAC has been conducted with populations other than parents, but did not report results separately by gender. Undergraduate students' ratings of treatments were assessed before and after receiving information (Singh \& Katz, 1985). Ratings of three behavioral techniques and one humanistic treatment for child behavior problems were obtained from 96 undergraduate students at baseline. Students then received a 5-hour didactic session on behavioral treatments and rated the four treatments again. Results indicated that students rated the behavioral treatments more favorably after receiving information about those treatments, while ratings of the humanistic procedure were unaffected. Tingstrom (1989) replicated this study with the addition of a control group. The experimental group received the didactic session and the control group received no training. Ratings of behavioral treatments improved in the experimental group following training and the control groups' ratings were unchanged.

Tarnowski, Mulick, and Rasnake (1990) investigated the acceptability of treatments used to address self-injurious behaviors. Direct-care staff of individuals exhibiting self-injurious behaviors rated six behavioral treatments including differential reinforcement of other behaviors, differential reinforcement of incompatible behaviors, stimulus control, overcorrection, physical restraint, and shock. The authors found that direct-care staff from behaviorally-oriented facilities rated the six behavioral treatments as more acceptable in the treatment of self-injurious behaviors than staff from nonbehavioral institutions. In contrast, Rasnake, Martin, Tarnowski, and Mullick (1993) found that direct-care staff's age and education level, but not treatment acceptability ratings, were associated with knowledge of behavioral principles. 
Herschell et al. (2005) examined two formats of BPT workshops. Individuals in the experiential group received individual feedback on skill acquisition, participation in role-plays, and individual practice of behavioral coding. Didactic group members, however, reviewed videotapes, engaged in discussion, and practiced coding as a group. These individuals did not receive individual feedback on performance as did experiential group members. Interestingly, both groups equally were effective in improving knowledge of behavioral principles, as well as observed skill and satisfaction.

Research also has found that knowledge of the social learning theory increases acceptability of behavioral treatments for young children exhibiting problem behaviors. McKee (as cited in Cross-Calvert \& Johnston, 1990) divided teachers into two groups based on their knowledge of social learning principles (i.e., high knowledge and low knowledge). Teachers in the high knowledge group rated four behavioral classroom interventions as more acceptable than teachers exhibiting little knowledge of social learning principles. In addition, teachers demonstrating knowledge of behavioral principles provided a higher rating of social skills training programs for students than teachers demonstrating little or no knowledge of behaviorally-oriented information (Clark \& Elliott, 1988).

Research on knowledge of behavioral principles has indicated that satisfaction with behavioral techniques increases upon receiving information about these strategies. However, recent studies evaluating behavioral knowledge have been conducted with nonparental samples and failed to report scores separately for men and women, and no studies were found comparing mothers and fathers on knowledge of behavioral principles in regard to child behaviors. Thus, whether mothers and fathers demonstrate similar levels of knowledge of behavioral principles either prior to or following training in these strategies is unknown. 


\section{Observed Parent Behaviors}

Behavioral observations typically are considered to be a relatively objective means of gathering information about behaviors. This technique provides actual data on parental behaviors, as opposed to relying on self-report data that may be biased and inaccurate. Compared to the literature on mother-child interactions, few studies have conducted behavioral observations of father-child interactions from either community or referred samples (e.g., Webster-Stratton, 1990, 1992; Webster-Stratton \& Hammond, 1997). Thus, little is known about fathers' observed techniques when interacting with their children.

The limited studies that include behavioral observations of mother- and father-child interactions have demonstrated that mothers and fathers exhibit different behaviors with their children. When talking to their children, fathers in a community sample ask more questions than mothers (Leaper, Anderson, \& Sanders, 1998; Rowe, Coker, \& Pan, 2004). Some studies also have found that mothers used more positive parenting behaviors than fathers with their children. For example, mothers in Calzada, Eyberg, Rich, and Querido's (2004) study used more positive behaviors (both verbal and physical) with their disruptive children than fathers. Similarly, using a referred sample, Robinson and Eyberg (1981) found that mothers used more praise than fathers when interacting with their children in parent-child dyads. Groups of mothers and fathers, both referred and community samples, in the same study differed in their use of praise statements in that mothers in some groups praised more than fathers while the opposite was true in other groups (e.g., more praise from treatment group mothers and control group fathers; Leaper, Anderson, \& Sanders; Webster-Stratton, 1990; Webster-Stratton, 1992; Webster-Stratton \& Hammond, 1997). In addition, Russell and Russell (1987) found that fathers from a community sample engaged in more neutral interactions with their children than mothers, while mothers 
utilized more positive and negative affective responses (Russell \& Russell, 1987). No general conclusions from this literature can be drawn due to the contradictory findings on maternal and paternal positive parenting behaviors.

Data from additional literature examining mother- and father-child interactions provide conflicting results, as well. For example, in an investigation of community families, Kazura (2000) and Clevenger-Bright and Stockdale (1984) reported that fathers tend to engage in controlling behaviors with their children more often than mothers, but other studies reported the opposite finding with children exhibiting both typical and disruptive behaviors (Buhrmester, Camparo, Christensen, Gonzalez, \& Hinshaw, 1992; Patterson, 1982). With regard to the use of commands, some studies with both clinical and nonclinical samples have found that fathers use more commands with children (e.g., Leaper, Anderson, \& Sanders, 1998; Robinson \& Eyberg, 1981), while others find that mothers use more commands (Patterson, 1980). Conflicting data are found with other parental behaviors as well (e.g., commands, critical statements; WebsterStratton, 1990). These opposite findings of parental behavior may impede the ability to draw generalized conclusions about the actions of each parent. Thus, the specific parent behaviors to target in BPT would differ from parent dyad to parent dyad.

Child behavior also has been found to differ in interactions with mothers versus fathers. Boys exhibiting normal or hyperactive behaviors in Buhrmester et al.'s (1992) study were more negative in interactions with mothers than fathers. Children also have exhibited differences in compliance depending on the parent with whom they are interacting. More specifically, children with disruptive behaviors followed fathers' instructions more often than commands given by their mothers (Calzada, Eyberg, Rich, \& Querido, 2004). However, no consistency in child disruptive behavior between parents was found. Some clinically-referred children engaged in 
more deviant behaviors (e.g., whine, smart talk, destructive) with mothers, while fathers in other groups experienced more of these behaviors from their children (Webster-Stratton, 1990; 1992; Webster-Stratton \& Hammond, 1997).

Although some mothers and fathers differ in their interactions with their children, other data have pointed out similarities in these dyads as well. In ten-minute interactions (five minute play interaction, five minute clean-up situation) with their children, mothers and fathers engaged in similar positive and negative behaviors toward their children (Ehrlick, Gimpel, \& Veeder, 2004). Additionally, MacDonald (1988) found that boys with hyperactivity experienced comparable responses from their mothers and fathers, while parents of children with conduct problems showed no difference on behavioral observations (Webster-Stratton, 1988). In addition to similarity in parental behaviors with children, children's responses toward their parents also have been found to correspond between mothers and fathers (Ehrlick, Gimpel, \& Veeder). In examining mother- and father-child dyads, children in Robinson and Eyberg's (1981) study engaged in similar rates of compliance and disruptive behaviors with their mothers and fathers.

Results from studies examining behavioral observations of maternal and paternal parenting behaviors make generalization of findings to a larger population difficult. For example, inconsistent findings have been reported for mother- and father-child interactions (e.g., some studies report more commands from fathers and others from mothers). In addition, dyadic interactions were observed under various conditions (e.g., freeplay, cleanup) with a variety of coding systems. Finally, some research was conducted with normative samples while other studies involve clinical samples. Because of the inconsistent findings, it is premature to draw conclusions about the similarities and differences in mothers' and fathers' parenting skills. 


\section{Summary}

In sum, most studies examining parenting programs have been conducted with mothers. In evaluating treatment acceptability, mothers and fathers differed in their satisfaction ratings with respect to various treatments used with children. Behavior observations of parental behavior have provided conflicting results. For example, some studies found that mothers engaged in more negative behaviors with their children than fathers while other studies found the opposite. Other research reported no differences in behavior between parents when interacting with their children. Similarly, some studies found that children exhibited different behaviors with mothers than fathers, while other studies found only similarities. Although research has indicated that parental knowledge of behavioral principles increases following parent training groups and therapy, no studies were found that compared knowledge of behavior principles of mothers and fathers receiving BPT. Additionally, the one study (i.e., Miller \& Kelley, 1992) that compared a normative sample of mothers and fathers on treatment acceptability found that mothers preferred positive reinforcement while fathers preferred spanking. No studies were found comparing normative samples of mothers and fathers on knowledge of behavioral principles or observed behaviors. However, in comparing the observed parent behaviors of normative fathers and fathers with children exhibiting disruptive behaviors, the two groups were discriminated by child compliance, child inappropriate behavior, and father inappropriate behavior (Brestan, Foote, \& Eyberg, 2004). As fathers have been neglected in the literature examining parent programs and child behavior in general, data on paternal attitudes toward child treatment techniques as well as paternal parenting behaviors must be obtained. These data could increase understanding of fathers' views of child behavior and behavior modification techniques, thus providing knowledge about how to obtain active participation from fathers in parenting programs. 


\section{Purpose of the Study}

The purpose of the current study was to examine the treatment acceptability, knowledge of behavioral principles, and observed behavior of both mothers and fathers in a normative sample. Similar to Miller and Kelley (1992), the treatment acceptability of child interventions commonly used with child inappropriate behaviors were examined using normative sample mothers' and fathers' reports on the short form of the TEI. Unlike Miller and Kelley, the current study compared parental treatment acceptability to other measures (e.g., knowledge of behavioral principles, observed parent behaviors). In addition, this project provided updated information on treatment acceptability, as Miller and Kelley's study was conducted more than ten years ago. Both parents completed the Knowledge of Behavioral Principles as Applied to Children (KBPAC; O’Dell, Tarler-Benlolo, \& Flynn, 1979) questionnaire to assess their understanding of a variety of behaviorally-oriented techniques. Maternal, paternal, and child behaviors were observed and coded during parent-child interactions using some behaviors from the Dyadic Parent-Child Interaction Coding System-II (DPICS-II). This project examined the comparison of maternal and paternal data using repeated measures multivariate analyses of variance for treatment acceptability, observed parent behaviors, and observed child behaviors and a pairedsamples $t$ test for the knowledge of behavioral principles. Associations among the various measures were examined using correlational analyses.

Hypothesis one. It was hypothesized that mothers and fathers would differ on their ratings of treatment acceptability. Specifically, fathers were expected to rate spanking as a more acceptable form of discipline than mothers, while mothers were expected to rate positive reinforcement as more acceptable than fathers.

Hypothesis two. It was hypothesized that mothers and fathers would differ on their 
observed parenting behaviors. In particular, it was expected that fathers would engage in more controlling behaviors with their children than mothers. Additionally, mothers were expected to talk to their children more and to provide more praise statements than fathers.

\section{Method}

Setting

Data were collected in the home setting.

\section{Participants}

Participants were recruited by word-of-mouth and distribution of fliers. Fliers were distributed to local pre-schools, daycares, pediatrician offices, grocery stores, churches, and other local settings. Parents willing to participate either were contacted by telephone or contacted the experimenter themselves to schedule a data collection session. Participants included 80 parents (40 mother-father pairs) of a two-to seven-year-old male child. Approximately five families chose not to participate because the fathers did not wish to be videotaped while interacting with their children. If parents had more than one male child between the ages of two and seven, the parents were asked to choose whichever child was "most convenient" for the assessment (e.g., if one was in school and the other was at home, parents may feel it was most convenient to bring the younger child while the older one was in school). Participants must have been the primary caregivers of the child for the last two years. Only families with a male child served as participants because the majority of children in parent-training studies have been male (e.g., Eisenstadt, Eyberg, McNeil, Newcomb, \& Funderburk, 1993; Nixon, Sweeney, Erickson, \& Touyz, 2003; Webster-Stratton, 1992), and boys more frequently are referred for externalizing behaviors (Webster-Stratton, 2000). Finally, the limited child age range (two to seven) was determined because the direct observation measure was developed with children between the 
ages of two and seven and their parents (Eyberg \& Robinson, 1983).

Measures

Demographic form. Each mother and father completed a demographic form (Appendix A) to provide descriptive data on the parents, target child, and family. Information obtained on this form included the following: parent age, gender, race, marital status, education level, income, occupation, interaction with the target child, likelihood of obtaining psychological services for the child; child age, race, and time with other caregivers; number of children in the home; and ages of other children. An involvement variable was calculated by the sum of the hours spent engaging in caregiving and play activities on a typical week day and the hours spent engaging in caregiving and play activities on a typical weekend day. Data obtained from the demographic form were used to provide descriptive information about the sample and to determine if mothers and fathers significantly differed on any of these variables.

Hollingshead. The Hollingshead Index score (Hollingshead, 1957) is a social position score derived from a two-factor index. As previously indicated, parental income and education level were obtained on the demographic form. These data (i.e., income and education) provided the two factors used to calculate the family's social position score. Occupation and education level were assigned scores based on categories found in the Hollingshead index. These scores were used in a formula where both the occupation and education scores were multiplied by a weighted factor score and those products were summed. This summation was the social position score. In addition, a social class score (i.e., Class I = upper class; Class III = middle class; Class $\mathrm{V}=$ lower class) was provided based on the social position score. Higher scores on the Hollingshead indicated a lower socioeconomic status.

Eyberg Child Behavior Inventory (ECBI). Each mother and father participant completed 
an ECBI on the target child (Appendix B). Information obtained from this measure was used as demographic data to describe the behavior of the child sample. The ECBI (Eyberg \& Pincus, 1999) is a 36-item questionnaire examining child disruptive behavior as reported by the parent(s). This instrument was developed to assess the behavior of children, age two to sixteen years, on two scales. The Intensity scale measures the frequency of child externalizing behaviors on a scale of 1 (Never) to 7 (Always). The Problem scale measures whether the parent perceives each of the listed child behaviors as a problem for that parent. The number of items receiving a response of "Yes" on the Problem scale are summed providing a total Problem score. Clinical cutoff scores of $132(\mathrm{~T}$-score $=60$; Intensity scale $)$ and $15(\mathrm{~T}$-score $=60$; Problem scale $)$ have been suggested by Colvin, Eyberg, and Adams (1999). Good psychometric data have been reported for the ECBI. For example, both scales demonstrated high internal consistency $($ Intensity $=.95$, Problem $=.92)$. In addition, both scales have demonstrated discriminative validity, construct validity, and interparent agreement (Colvin et al.; Eyberg \& Pincus). Finally, the test-retest reliability of the Intensity scale was reported for 12 weeks $(r=.80)$ and 10 months $(r=.75 ;$ Funderburk, Eyberg, Rich, \& Behar, 2003).

Treatment Evaluation Inventory-Short Form (TEI-SF). To assess maternal and paternal acceptability of techniques often used to combat child behaviors, each mother and father completed the TEI-SF (Kelley, Heffer, Gresham, \& Elliott, 1989). Parents read a case description of a male child exhibiting behaviors consistent with a diagnosis of Oppositional Defiant Disorder and vignettes of six different interventions (i.e., differential attention, overcorrection, positive reinforcement, response cost, spanking, and timeout; see Appendix C) to address the child behaviors. Each parent then rated his or her acceptability of each of the interventions using the TEI-SF (see Appendix D). Thus, each parent completed six total TEI-SFs (one for each 
vignette). The TEI-SF, an abbreviated version of the TEI (Kazdin, 1980a; 1981; 1984), is a 9item questionnaire that assesses acceptability of various treatments often used with children. The original version of the TEI was adapted for a variety of reasons. First, many of the original TEI individual items contained too many words and as a result, were difficult to read. Second, only a portion of the 7-point Likert scale was used in reporting results. Finally, Kelley et al. removed repetitive items to shorten the scale's length and increase comprehensibility. The items on the TEI-SF are rated on a 5-point Likert scale ranging from 1 (strongly disagree) to 5 (strongly agree). However, item 6 is reverse scored. TEI-SF scores can range from 9 to 45, with a score of 27 indicating an overall rating of moderate acceptability (Kazdin, 1981). Initial psychometric properties of the TEI-SF are promising (good internal reliability and validity), but more research must be conducted to further evaluate this instrument. The case description and six vignettes were obtained from Jones, Eyberg, Adams, and Boggs (1998).

Knowledge of Behavioral Principles as Applied to Children (KBPAC). The original KBPAC (O’Dell, Tarler-Benlolo, \& Flynn, 1979) is a 50-item multiple choice questionnaire that evaluates familiarity with behaviorally-oriented strategies as applied to children. The authors were careful to use general language and avoid the use of behavioral vocabulary in this measure. The KBPAC presents scenarios of common child behaviors to which the respondent is to choose the best technique to address the child's actions. The techniques used in this measure include reinforcement, punishment, schedules, shaping, differential attention, extinction, and monitoring behavior.

The KBPAC is a lengthy questionnaire requiring 30 to 60 minutes to complete. As a result, 10- and 25-item versions of this measure were developed (Furtkamp, Giffort, \& Schiers, 1982). The 25-item KBPAC has two forms (A and B). Because participants in this study only 
were assessed at one time point, one version of the KBPAC was used for this study (form A; see Appendix E for KBPAC). This shortened version of the KBPAC has demonstrated psychometric data similar to the 50-item KBPAC. In addition, a range of internal consistencies has been reported for this version (Cronbach's alpha = .42 - .84; Sturmey, Newton, Milne, \& Burdett, 1987). It is important to note that the KBPAC has not been validated with mothers or fathers. Dyadic Parent-Child Interaction Coding System-II (DPICS-II). The DPICS-II (Eyberg, Bessmer, Newcomb, Edwards, \& Robinson, 1994) is a behavioral observation coding system developed to assess and quantify parent-child interactions in three five-minute standard situations (i.e., Child Directed Interaction, CDI; Parent Directed Interaction, PDI; and Clean-up, $\mathrm{CU})$. In the CDI situation, the parent was instructed to let the child choose what to play with and to follow the child's lead. In the PDI situation, parents chose the toy and lead the play. Finally, clean-up involved the parent telling the child to clean up all the toys without the parent's assistance. (See Appendix F for situation instructions). These three situations provided data on both parental and child behaviors in a variety of contexts. The DPICS-II contains 26 behavioral categories that include parent and child verbalizations, vocalizations (e.g., whine, laugh, and yell), and physical behaviors (e.g., positive and negative touch). The authors, however, indicate that the DPICS-II can be adapted to investigate specific research questions. As the current investigation compared mothers' and fathers' interactions with their children, all parent verbalizations, child responses to commands (e.g., comply or noncomply), and child negative behaviors (e.g., yelling, whining) were recorded (see Appendix G for coding sheet). Parent verbalizations examined included positive, aversive, and controlling behaviors and all parental verbalizations were summed to provide an amount of parental interaction total (see Appendix $\mathrm{H}$ for definitions). A percentage of child compliance was calculated by dividing the total number of 
child complies by the total number of parental commands. Graduate and advanced undergraduate research assistants reviewed videotaped parent-child interactions and transcribed those interactions. Both parent and child behaviors were coded from the transcripts. Frequency counts of each behavior were summed for that behavior category of that parent and child across the three standard situations to provide a total count.

Eyberg et al. reported that no reliability data exist on the entire DPICS-II coding system. The authors suggested that because the DPICS-II is quite similar to the original DPICS (Robinson \& Eyberg, 1981), psychometric data for the DPICS should reflect the DPICS-II as well. Robinson and Eyberg examined interrater agreement on the three observation situations for coders and reported a reliability coefficient of .91 for parent categories and .92 for child categories. This coding system also has been found to discriminate between children with and without behavior problems as well as parents of referred versus nonreferred children (Robinson \& Eyberg; Webster-Stratton, 1985). Preliminary data on the DPICS-II suggest that this coding system also can discriminate between referred and nonreferred samples (children and their parents; Bessmer \& Eyberg, 1993).

Interrater agreement. Interrater agreement data were collected for $20 \%$ of the families' interactions. Observations coded randomly were chosen by the author. Cohen's Kappa (Cohen, 1988) was generated on all dependent variables in the study: positive behavior, aversive behavior, controlling behavior, child negative behavior, and child compliance. If any of the calculated Kappa statistics fell below .60 on three consecutive occasions, the coder would cease coding and be retrained until a .75 Kappa was obtained between the two coders. Interrater agreement did not fall below .60 Kappa on three consecutive occasions, thus no retraining was required. Research assistants were unaware of the study hypotheses and which interactions were 
chosen for interrater agreement assessment. Average interrater agreement Kappas for dependent variables were as follows: positive behavior $=.96(.93-.98)$, aversive behavior $=.87(.50-1.00)$, controlling behavior $=.97(.93-.99)$, child negative behavior $=.96(.80-1.00)$, and child compliance $=1.00$.

Procedure

Coder Training. Coders demonstrated competency on various coding exercises prior to this study. More specifically, coders participated in weekly coding training meetings for five months. During these meetings, research assistants read and discussed behavioral codes from the DPICS-II training manual. Scores of $90 \%$ or above were obtained on all exercises and quizzes before advancing to another behavioral coding category (Eyberg et al., 1994). Following completion of all manual work, research assistants coded transcriptions of parent-child interactions and then videotaped interactions (of families who were not in the current study) both individually and as a group. Coders achieved a Kappa of . 75 on all codes during a coding test (using transcriptions or videotaped interactions) before coding data for the current project.

Paper and pencil measures. Each mother and father participant completed paper and pencil questionnaires including a demographics form, ECBI, 6 TEI-SF measures (one for each vignette), and the KBPAC. One parent completed these forms while the other parent engaged in a videotaped interaction with the child.

Parent-child interactions. Each mother and father engaged in a 15-minute interaction with their child. Each parent-child dyad participated in three standardized five-minute interactions. As previously discussed, the three interaction situations were CDI, PDI, and CU, conducted in this order for all participants. Parents were given standardized instructions for each situation (presented in Appendix F). Except for providing instructions to the parent, research 
assistants refrained from communicating with the parent and child until the 15-minute interaction was finished. To summarize these situations, the child lead the play in CDI, the parent lead in PDI, and only the child cleaned up the toys in CU. These situations provided a glimpse of parent and child behaviors in various contexts. All interactions were videotaped. The order of who completed the interaction or paper and pencil measures first was chosen randomly from family to family.

Behavior coding. All videotaped parent-child interactions were transcribed and then coded by graduate and undergraduate research assistants. Spot checks of transcribed data were conducted on approximately $10 \%$ of the interactions to ensure the reliability of converting videotaped interactions to transcriptions. No errors that changed the coding were found. Frequency counts of parent and child behaviors exhibited during these dyadic interactions were coded using the DPICS-II target behaviors chosen for this study. Frequencies of behavioral categories (both child and parent), except percent child compliance, were summed to provide a total count for those behaviors. Parent behaviors coded included positive behavior, aversive behavior, controlling behavior, and amount of interaction, while compliance and negative behaviors were coded for the children (see Appendix $\mathrm{H}$ for definitions of behavior codes). Incomprehensible verbalizations were excluded from the data, while verbalizations that do not correspond with a DPICS-II category were coded as "other."

Results

\section{Demographic Characteristics}

Demographic characteristics of the sample are in Table 1. Parents were $34.24(S D=6.40)$ years old and children were $4.65(S D=1.65)$ years old. The average parental rating of child behavior on the ECBI was below the clinical cutoff for behavior problems $(\mathrm{T}$ score $=52)$. Raw 
scores on the ECBI intensity scale ranged from 61 to 162 (T scores $=40$ to 69$)$, and problem scores ranged from 0 to 22 ( $\mathrm{T}$ scores $=41$ to 69 ) with $5 \%$ of parents rating their child's behavior in the clinical range. In addition, the majority of the sample was Caucasian (98.75\% for parents and $97.50 \%$ for children) and married (95\%). Finally, ninety-five percent of the parents were the biological parents of the child.

Demographic characteristics of the parents based on gender are provided in Table 2. Results of paired-samples $t$ tests did reveal differences between parents on demographic variables. More specifically, fathers were significantly older than mothers, $t(39)=-5.858, p<$ .001 , and mothers spent significantly more time interacting with their child (i.e., involvement) than fathers, $t(39)=-3.688, p<.01$.

Involvement was determined by parental report of the sum of the amount of time spent in caregiving and play activities on a typical week day and a typical weekend day. As previously stated, mothers spent significantly more time in these activities $(M=16.89, S D=5.93)$ than fathers $(M=12.35, S D=6.12)$. Maternal and paternal report of the percent of caregiving activities that the father completed were positively correlated, $r(39)=.530, p<.01$, indicating the parents agreed about the level of father involvement. However, parental ratings of the percent of caregiving activities completed by the mother were not correlated, $r(39)=.285, p=.07$, suggesting disagreement about maternal involvement. Fathers' report of maternal participation in caregiving activities $(M=68.1)$ was higher than mothers' own report of participation in these activities $(M=66.5)$.

\section{Treatment Acceptability}

A repeated-measures MANOVA was conducted to evaluate treatment acceptability of mothers and fathers. The Parent $\mathrm{x}$ TEI interaction effect was significant, Wilks' $\Lambda=.51, F(5,35)$ 
$=6.82, p<.001$. Six paired-samples $t$ tests were conducted to follow up the significant interaction. Mothers rated response cost significantly higher than fathers, $t(39)=2.498, p<.05$, while fathers rated spanking more favorably than mothers, $t(39)=-4.191, p<.001$. These results partially support hypothesis one suggesting that fathers would rate spanking higher than mothers. However, the hypothesis that mothers would be more accepting than fathers of positive reinforcement was not supported. It is important to note that parents rated spanking as the least acceptable strategy of all techniques assessed $(M=23.19, S D=7.56)$. The standardized effect size index, Cohen's $d$, was .40 for response cost, indicating a small-to-medium effect size, and .66 for spanking, indicating a medium effect size. Refer to Table 3 for treatment acceptability results.

\section{Knowledge of Behavioral Principles}

A paired-samples $t$ test was conducted to evaluate whether mothers and fathers differed in their knowledge of behavioral principles. Mothers' average percentage on the KBPAC was $44.86(S D=13.00)$ and $42.00(S D=14.15)$ for fathers. Results indicated that mothers and fathers exhibited similar knowledge of behavioral principles, $t(39)=1.158, p=.254$.

\section{Observed Behaviors}

A repeated-measures MANOVA was conducted to evaluate whether mothers and fathers differed on their observed parenting behaviors and whether child behavior varied with mothers and fathers. The Parent $x$ Observe interaction effect was significant, Wilks' $\Lambda=.75, F(4,36)=$ $3.05, p<.05$. Five paired-samples $t$ tests were conducted to follow up the significant interaction. Mothers provided significantly more positive verbalizations to their child than fathers, $t(39)=$ $2.674, p<.05$. The strength of the effect, as measured by Cohen's $d$, was .42 , indicating a small effect size. See Table 4 for observed parenting behaviors results. Additional analyses on 
individual behaviors coded in the positive behavior composite revealed that as compared to fathers, mothers exhibited significantly more information descriptions, $t(39)=2.197, p<.05$, and reflections, $t(39)=2.373, p<.05$. Fathers did not engage in more controlling behaviors with their children than mothers, $t(39)=.833, p=.41$, nor did mothers talk more to their children, $t(39)=1.602, p=.117$, or provide more praises than fathers, $t(39)=1.120, p=.270$. Thus, hypothesis two was not supported.

\section{Father Involvement}

Bivariate correlational analyses examining the associations between father involvement and the dependent variables were conducted (see Table 5). The following comparisons with father involvement revealed significant positive correlations: response cost and observed child negative behavior. More specifically, greater time spent by fathers in child-related activities was associated with more favorable ratings for response cost, $r(39)=.316, p<.05$ and more negative child behaviors exhibited during observed father-child interactions, $r(39)=.396, p<$ .05. Refer to Table 5 for additional significant positive correlations in the father involvement bivariate correlational matrix.

\section{Correlations}

Correlational analyses examining the associations between demographic variables and treatment acceptability and knowledge of behavioral principles were conducted (see Table 6). Bivariate correlational analyses conducted with the TEI-SF acceptability ratings revealed significant negative correlations between response cost acceptability and parent age, $r(39)=$ $-.27, p<.05$, and response cost and child age, $r(79)=-.25, p<.05$. These correlations indicated that the younger the parents and the child, the more the parents liked response cost. Response cost was positively correlated with involvement, $r(79)=.29, p<.05$, and overcorrection, $r$ (79) 
$=.24, p<.05$. These results suggest that the more parents favor response cost, the more time they spent in father-child interactions and the more acceptance of overcorrection they reported. Acceptability of spanking was negatively correlated with involvement, $r(79)=-.28, p<.05$, such that more involved parents rated spanking as less acceptable. Acceptability of timeout was negatively correlated with parent age, $r(79)=-.26, p<.05$. This negative correlation suggests that the older the parents were, the less they liked timeout. Negative correlations were found between knowledge of behavioral principles and the Hollingshead Index (social position), $r$ (79) $=-.26, p<.05$, child behavior problems as rated on the ECBI Intensity scale, $r(79)=-.31, p<$ .01 , and acceptability of spanking, $r(79)=.27, p<.05$. These correlations suggest that the higher the knowledge of behavioral principles, the lower the social position score (higher social class), child behavior problems, and acceptability of spanking. See Table 6 for further significant correlations. An additional significant correlation was found between parental education level and knowledge of behavioral principles, $r(79)=.444, p<.0001$, suggesting that the higher the education level of the parent, the higher the knowledge of behavioral principles.

Bivariate correlational analyses examining the associations between demographic variables and observed behaviors and knowledge of behavioral principles were conducted (see Table 7). The aversive behavior composite was positively correlated with the positive behavior composite, $r(79)=.31, p<.01$, the controlling behavior composite, $r(79)=.35, p<.01$, and the child negative behavior composite, $r(79)=.39, p<.01$ indicating that the more aversive verbalizations the parents used, the more positive and controlling verbalizations used and the more negative behaviors the child exhibited. The controlling behavior composite was negatively correlated with child age, $r(79)=-.55, p<.01$ and positively correlated with the ECBI Intensity scale, $r(79)=.23, p<.05$ and positive behavior composite, $r(79)=.46, p<.01$. These 
correlations indicate that the more controlling verbalizations the parents used, the younger the child, the higher the parents rate child behavior problems, and the greater the number of positive parental verbalizations used in parent-child interactions. Child negative behavior was positively correlated with involvement, $r(79)=.25, p<.05$ and the controlling behavior composite, $r$ (79) $=.23, p<.05$, indicating that the more negative behaviors the child engaged in with parents, the more involved the parents were with the child and the more controlling parental verbalizations the parents utilized. The child negative behavior composite also was negatively correlated with child age, $r(79)=-.30, p<.01$, suggesting that number of negative child behaviors increased with age. Finally, knowledge of behavioral principles was negatively correlated with parental controlling behavior, $r(79)=-.23, p<.05$, indicating that the more behavioral knowledge parents possessed, the less controlling behaviors they exhibited when interacting with their children.

\section{Discussion}

The present study compared maternal and paternal reports of treatment acceptability of child behavior management strategies and knowledge of behavioral principles, as well as observed parent and child behaviors during a dyadic interaction. Results revealed that parents did differ on treatment acceptability and observed behaviors. However, children did not interact differently with their parents. In addition, mothers and fathers exhibited similar knowledge of behavioral principles.

\section{Treatment Acceptability}

Mothers and fathers reported different acceptability ratings for child behavior management strategies outlined in the TEI-SF. More specifically, mothers favored response cost more than fathers, while fathers liked spanking more than mothers. These findings provide 
partial support for the first hypothesis that fathers would rate spanking higher than mothers, while mothers would rate positive reinforcement higher than fathers. In addition, results are consistent with Miller and Kelley's (1992) findings that when compared, mothers favored response cost and fathers favored spanking. In previous research as well as this study, mothers spend more time with their children than fathers. This extra time may have given mothers the opportunity to implement a variety of discipline techniques in an attempt to find the most effective strategy for reducing inappropriate child behavior. As mothers favor positive procedures and fathers favor more intrusive techniques, mothers may have avoided utilizing spanking as a form of discipline and only used punishment they felt comfortable implementing. In addition, restriction of privilege (response cost) may be easier for mothers to use with older children than a hands-on type of discipline (spanking). It also is possible that response cost may be easier to implement in families with numerous children. It is important to note, however, that a score of 27 on the TEI-SF indicates moderate acceptability of a strategy. Both parents' ratings of spanking were below 27. Thus, consistent with Miller and Kelley, although fathers were more accepting of spanking than mothers, fathers were less than moderately accepting of spanking.

Acceptance of various behavior management strategies was correlated with numerous variables. First, intrusive techniques were significantly correlated with each other. In particular, timeout was positively correlated with overcorrection and response cost, and response cost and overcorrection were correlated. Timeout involves removing stimulation, response cost removes privileges, and overcorrection involves repetition of appropriate behavior to correct negative behavior and at times, physical guidance. Thus, parents who agreed with the removal of stimulation through timeout also favored response cost and overcorrection. The mean acceptance scores of parents in this study were similar to those of mothers in a study by Jones, Eyberg, 
Adams, and Boggs (1998). Average acceptability scores for parents in this study were 32.35 for timeout, 34.68 for response cost, and 28.23 for overcorrection while averages for Jones et al.'s study were 32.55 for timeout, 33.35 for response cost, and 29.20 for overcorrection. These scores suggest that parents' level of acceptability is above the moderate acceptability range for these behavior management strategies. Parents in the present study, however, reported less than a moderate acceptability for differential attention and spanking.

Treatment acceptability also was correlated with parent age and involvement in caregiving and play activities. Results suggest that younger parents like response cost and timeout more than older parents. Younger parents would tend to have younger children than older parents. Thus, response cost and timeout procedures may be implemented more easily and used more often with younger children as opposed to older children. In addition, parental involvement with child-related activities was associated with acceptability of response cost and spanking. More specifically, more-involved parents liked response cost more and spanking less than parents with little involvement in caregiving and play activities. These results indicate that when implementing punishment for child misbehavior, parents who spend more time with their children choose restriction of privilege instead of spanking.

Knowledge of Behavioral Principles

Mothers and fathers did not differ on their knowledge of behavioral principles as measured by the KBPAC. This finding may be attributed to similar social position scores for mothers and fathers. Education and occupation are used in calculating the Hollingshead social position index. Similar social position scores suggest similar education levels and occupations for parents. In this study, both the Hollingshead Index and education level were positively correlated with the KBPAC. The correlation between education and KPBAC indicates that more 
educated parents exhibited greater knowledge of behavioral principles. However, it is important to note that the average percentage for parents on the KBPAC was $43 \%$ out of $100 \%$. This score is similar to previous research conducted with parents and the KBPAC. Parents in a study by O'Dell, Tarler-Benlolo, and Flynn (1979) obtained an average of $48 \%$ on the KBPAC prior to attending a child behavior management training. The mean KBPAC percentage in this study is similar to scores reported for other populations as well. Specifically, various samples of individuals working with populations with developmental disabilities included direct care staff scoring an average of 51\% (Furtkamp, Giffort, \& Schiers, 1982); professionals nurses, occupational therapists, psychiatrists, and physiotherpists obtaining 49\% (Sturmey, Newton, Milne, \& Burdett), and school staff achieving a mean of 52\% (Sturmey et al.). However, community mental health agency therapists' mean KBPAC score of $64 \%$ is somewhat higher than the $43 \%$ obtained by parents in this study (Herschell et al., 2005). The majority of therapists (almost 90\%) in Herschell et al.'s study, however, had masters-level degrees, while parents in the present study reported, on average, completing "some college." These discrepancies in education and scores on the KBPAC between the present study and Herschell et al. may support the idea that education, particularly education in mental health, increases knowledge of behavioral principles.

Parent scores on the KBPAC were significantly correlated with several additional variables. Interestingly, the older the parent and the child, the more knowledge of behavioral principles the parents exhibited. This finding may be due to parenting experience. The older the parent and the child, the more years the parents would have with the child. Thus, parents would have increased experience with parenting practices and more time to try a variety of behavior management strategies as the years pass. This experience with behavior management may lead to 
an increase in parental knowledge of behavioral principles. In addition, results indicated that knowledge of behavioral principles affects parent report of child behavior problems. More specifically, parents with greater knowledge of behavioral principles reported less externalizing behaviors in their children. This correlation between knowledge and behavior problems also may be influenced by parental experience with managing behavior. It would be expected that as parents gain more experience with implementing discipline techniques and knowledge of behavioral principles, ability to handle child externalizing behaviors would improve thus decreasing the frequency of behavior problems. More knowledge of behavioral principles indicated less acceptance of spanking as a means of decreasing child inappropriate behaviors. This finding suggests that as parents understand behavioral principles and successfully extinguish disruptive behaviors by implementing effective behavior management strategies, the need to resort to physical punishment would decrease. Thus, parents with greater knowledge of behavioral principles may choose nonphysical forms of discipline and rate spanking as a less acceptable means of punishment. Finally, more knowledge of behavioral principles was associated with less parental controlling behaviors toward the child. This finding may indicate that parents who understand behavioral principles utilize effective behavior management strategies and infrequently rely on directive behaviors when interacting with their child.

\section{Observed Behaviors}

Although mothers and fathers differed in their interactions with their child, child behavior did not vary between parents. Specifically, mothers exhibited more positive verbalizations than fathers when interacting with their child. In fact, mothers used more information descriptions and reflections when speaking to their children than fathers. As fathers did not exhibit more controlling behaviors with their children than mothers, and mothers did not talk more to their 
children or give more labeled praise statements than fathers, hypothesis two was not supported. The results of observed behaviors suggest that when interacting with their children, mothers will use neutral statements and reflect what their child is saying. Hembree-Kigin and McNeil (1995) indicate that the use of reflections provides social attention for child behavior and verbalizations. In addition, reflective statements indicate to the child that the parent is listening. As previously stated, mothers and fathers did not differ in their use of labeled praise statements as hypothesized. The similarity in use of labeled praises between parents may be explained by a floor effect. In fact, each parent engaged in a mean of less than one labeled praise in fifteen minutes. Thus, the low number of labeled praises used may make it difficult to detect a statistically significant difference between parents. As parents only differed on the positive behavior composite, mothers and fathers of the same child tended to behave similarly with their child. Children of these mother-father pairs interacted similarly with their parents as well. No studies were found that reported using mother-father pairs to compare maternal and paternal variables. A possible explanation for similar parental behaviors in this study could be that parents of the same child will be consistent in their interactions with their child. In other words, mother-father pairs will utilize similar parenting techniques and behaviors and begin parenting alike. Moreover, with comparable parent behaviors, children are less likely to differ in their interactions with their parents.

\section{Father Involvement}

The impact of father involvement also was examined in this study. Results indicated that more-involved fathers are more accepting of response cost and encounter more negative child behaviors than less-involved fathers. Although fathers liked spanking more than mothers, fathers who spent more time with their children favored response cost over all other behavior 
management strategies as compared to fathers spending less time with their children. This finding may have implications for BPT, suggesting that BPT programs likely will be more accepted by more-involved fathers than less-involved fathers. Thus, clinicians and researchers may have to make special efforts to reach and encourage participation from less-involved fathers.

Interestingly, the more time fathers spent with their children, the more negative behaviors the child exhibited during father-child interactions. This finding may be due to the idea that more time spent with the child allows for more opportunities for children to engage in negative behaviors with their fathers. Other studies have reported that mothers rating children as more disruptive than fathers may be attributed to the amount of time mothers spend with their children as compared to fathers (Duhig et al., 2000; Lewis \& Lamb, 2003). These authors further indicated that spending more time with children allows mothers to experience behavior problems more frequently and in more situations than fathers. This also may be true when comparing more- and less-involved fathers. In particular, more-involved fathers would experience more occurrences of problem behaviors that may have extended to the observed interactions in this study. An additional explanation for this finding is that children who spend more time with their fathers may feel more comfortable in interactions with their fathers than children experiencing less father-child time. Having more-involved fathers, may allow children many opportunities to express a variety of emotions and behaviors. It is possible that children, like adults, exhibit different behaviors in intimate relationships as opposed to less intimate relationships. For example, an adult might not raise a voice in anger to friends or colleagues. Yet, the same adult would be more likely to express anger in an intimate relationship with a spouse or partner, with whom he or she feels a close bond and high comfort level. Children also may be more likely to express negative affect and behaviors in closer relationships. Thus, children in this study may 
have displayed more disruptive behaviors with more-involved fathers, as compared to lessinvolved fathers, because of a greater comfort level in the relationship.

\section{Limitations}

Although the current study provides important data on the comparison of maternal and paternal variables, some limitations must be acknowledged with the interpretation of these results. First, numerous statistical analyses were performed in this study. Cohen (1988) reports that an increase in statistical tests also increases chances of committing Type I errors because significance may be obtained only due to the numerous tests conducted and the number of variables analyzed. Although the current study had 40 mother-father pairs, larger samples could have yielded additional significant results.

A second limitation of the study concerns generalizability of results. The sample in the current study had a high education level (finishing some college) and occupations that resulted in a high social class as measured by the Hollingshead. In addition, the average income for this sample was $\$ 66,000$. Thus, these comparisons of mothers and fathers may not generalize to families of either higher or lower social classes. All, but one parent was Caucasian limiting the ability to generalize findings to parents of various ethnic backgrounds and cultures. Only parents of male children were examined in this study to control for child gender effects. Parents of female children may yield different results than parents of male children. Also, a community sample was utilized and, on average, these children exhibited very infrequent behavior problems as reported by their parents. Thus, mothers and fathers of children engaging in clinically significant behavior problems may provide information that deviates from the current findings. Finally, this sample included mothers and fathers who were willing to both complete self-report measures and engage in videotaped interactions with their child. Willingness to participate may 
be an indication of level of parental involvement. Thus, this sample may not represent families in general, or particularly, families referred for BPT.

Additional limitations are associated with the assessments utilized in this study. First, social desirability could have influenced both parent responses on paper-pencil measures and observed interactions. Also, only six behavior management strategies typically used with clinicreferred children are evaluated on the TEI-SF. Thus, additional treatments, such as use of medication, are not considered (Jones, Adams, Eyberg, \& Boggs, 1998). Moreover, implementation of the six techniques on the TEI-SF is presented with specific examples. These vignettes do not present the variety of ways that each procedure could be employed. For example, the TEI-SF vignette for timeout discusses chair timeout. Parents may not agree with chair timeout, but with timeout in the child's bedroom. Therefore, the TEI-SF fails to measure acceptability of a variety of formats of each of the techniques. With the KBPAC, results of knowledge of behavioral principles with fathers were not found in the literature. This prevents comparison of paternal KBPAC scores in this study with KBPAC scores of other fathers. In addition, few studies have been conducted utilizing the KBPAC with parents. To provide normative data on parental knowledge of behavioral principles, additional studies must be conducted with parents and the KBPAC. The current study also did not evaluate experience with parenting or length of time as a parent. Parenting experience may impact treatment acceptability of behavior modification strategies, knowledge or behavioral principles, or observed parenting behaviors.

Further limitations should be noted concerning data from the observed interactions. First, as previously stated, social desirability could have influenced both parent and child behaviors during the videotaped interactions. In addition, parents were provided specific instructions to let 
the child lead the play, to lead the play themselves, and to have the child clean up all the toys without help. These structured situations may have elicited interactions that vary from unstructured play interactions. Videotaped interactions were transcribed, and then behaviors and verbalizations were coded from these transcriptions. Coding from transcriptions may have lost some of the meaning behind statements as well as voice intonation. Finally, each parent-child interaction only was 15 minutes in length providing a limited amount of behavioral data.

Different results could be obtained from either longer interactions or interactions observed across many days.

\section{Future Directions}

As research has pointed out, fathers infrequently are included in the literature concerning children (Budd \& O’Brien, 1982; Coplin \& Houts, 1991; Tiano \& McNeil, 2005). Thus, further research could expand upon the current results by addressing the limitations outlined above. First, additional research should be conducted with mother-father pairs reporting on the same child, as opposed to groups of mothers and fathers reporting on different children. Also, future studies could replicate the current study with a larger sample that includes parents and children from a variety of ethnic and socioeconomic backgrounds. In addition, comparisons of motherfather pairs of female children could be examined to determine if parents respond differently to female than male children. While the current study utilized a community sample, future research could be conducted with parents of children exhibiting clinically-elevated levels of behavior problems.

With regard to assessment instruments, presenting a variety of formats for each vignette of the TEI-SF should be examined to determine if parental acceptability ratings differ based on the examples used in the strategy descriptions. More recent research on the KBPAC has been 
conducted with populations other than parents, highlighting the need for additional studies examining parental knowledge of behavioral principles. In addition, no studies were found that separately reported paternal and maternal KBPAC scores. Similarly, Tiano and McNeil (2005) found that few studies of parents in behavioral parent training programs collected, reported, or analyzed paternal data independently from maternal data. Thus, future research should obtain, report, and compare maternal and paternal KBPAC scores to provide normative data of behavioral knowledge for mothers and fathers. Parent experience should be examined to determine whether this variable impacts parental report and behaviors. Additional research also should be conducted examining mother-father pairs' observed behaviors. More specifically, parent-child interactions should be examined utilizing unstructured situations to determine if parents or children behave differently when given no instruction. Finally, longer observations or more observation sessions should be conducted to provide more data on behaviors during parentchild interactions.

\section{Conclusion}

The current study provides some initial data on treatment acceptability, knowledge of behavioral principles, and observed behaviors with mother-father pairs of young male children. More specifically, mothers are more accepting of response cost than fathers, while fathers like spanking more than mothers, though both parents reported low acceptability of spanking. The only other study that compared maternal and paternal treatment acceptability found similar results. As only two studies are known to exist on this topic, the need for additional study in this area is clear. Although mothers and fathers in this study exhibited similar knowledge of behavioral principles, no additional studies were found that compared mother-father pairs' knowledge of behavioral principles highlighting the need for further research in this area. Also in 
this study, mothers engaged in more positive verbalizations during parent-child interactions than fathers. Father involvement was related to important parenting variables. In fact, more-involved fathers tended to express similar acceptability ratings as mothers. These favorable ratings are consistent with BPT techniques suggesting that more-involved fathers may be easier to recruit in BPT than less-involved fathers. 


\section{References}

Achenbach, T. M., \& Edelbrock, C. S. (1983). Manual for the child behavior checklist and revised child behavior profile. Burlington, VT: University Associates in Psychiatry.

Atwood, R., Gold, M., \& Taylor, R. (1989). Two types of delinquents and their institutional adjustment. Journal of Consulting and Clinical Psychology, 57, 68-75.

Bagner, D. M., \& Eyberg, S. M. (2003a). Father involvement in child treatment. In Ollendick, T. H., \& Schroeder, C. D. (Eds.), Encyclopedia of clinical child and pediatric psychology (pp. 235-236). New York: Plenum.

Bagner, D. M., \& Eyberg, S. M. (2003b). Father involvement in parent training: When does it matter? Journal of Clinical Child and Adolescent Psychology, 32, 599-605.

Bessmer, J., \& Eyberg, S. M. (1993). Dyadic Parent-Child Interaction Coding System-II (DPICS-II): Reliability and validity of the clinic version. Retrieved February 4, 2005, from http://www.pcit.org

Biller, H. B. (1993). Fathers and families: Paternal factors in child development. Westport, CT: Auburn House/Greenwood Publishing Company, Inc.

Brestan, E. V., \& Eyberg, S. M. (1998). Effective psychosocial treatments of conduct-disordered children and adolescents: 29 years, 82 studies, and 5,272 kids. Journal of Clinical Child Psychology, 27, 180-189.

Brestan, E. V., Eyberg, S. M., Boggs, S. R., \& Algina, J. (1997). Parent-child interaction therapy: Parents' perceptions of untreated siblings. Child and Family Behavior Therapy, 19, 13-28.

Brestan, E. V., Foote, R. C., \& Eyberg, S. M. (2004). The Dyadic Parent-Child Interaction Coding System II: Reliability and validity with father-child dyads. Unpublished manuscript. 
Budd, K. S., \& O’Brien, T. P. (1982). Father involvement in behavioral parent training: An area in need of research. The Behavior Therapist, 5, 85-89.

Buhrmester, D., Camparo, L., Christensen, A., Gonzalez, L. S., \& Hinshaw, S. P. (1992).

Mothers and fathers interacting in dyads and triads with normal and hyperactive sons. Developmental Psychology, 28, 500-509.

Calzada, E. J., Eyberg, S. M., Rich, B., \& Querido, J. G. (2004). Parenting disruptive preschoolers: Experiences of mothers and fathers. Journal of Abnormal Child Psychology, 32, 203-213.

Campbell, S. B. (1991). Behavior problems in preschool children: Clinical and developmental issues. New York: Guilford Press.

Campbell, S. B., March, C. L., Pierce, E., Ewing, I. J., \& Szumowksi, E. K. (1991). Hard-tomanage preschool boys: Family context and the stability of externalizing behavior. Journal of Abnormal Child Psychology, 19, 301-310.

Christensen, A., Margolin, G., \& Sullaway, M. (1992). Interparental agreement on child behavior problems. Psychological Assessment, 4, 419-425.

Clark, D. B., \& Baker, B. L. (1983). Predicting outcome in parent training. Journal of Consulting and Clinical Psychology, 51, 309-311.

Clark, L., \& Elliott, S. N. (1988). The influence of treatment strength information on knowledgeable teachers' pretreatment evaluation of social skills training methods. Professional School Psychology, 3, 253-269.

Clevenger-Bright, M., \& Stockdale, D. F. (1984). Mothers', fathers', and preschool children's interactive behaviors in a play setting. The Journal of Genetic Psychology, 144, 219-232. 
Cohen, J. (1988). Statistical power analysis for the behavioral sciences ( $2^{\text {nd }}$ ed.). New York: Academic Press.

Colvin, A., Eyberg, S. M., \& Adams, C. D. (1999). Restandardization of the Eyberg Child Behavior Inventory. Retrieved February 4, 2005, from http://www.pcit.org

Coplin, J. W., \& Houts, A. C. (1991). Father involvement in parent training for oppositional child behavior: Progress or stagnation? Child and Family Behavior Therapy, 13, 29-51.

Cross-Calvert, S., \& Johnston, C. (1990). Acceptability of treatments for child behavior problems: Issues and implications for future research. Journal of Clinical Child Psychology, 19, 61-74.

Dickson, K. L., Walker, H., \& Fogel, A. (1997). The relationship between smile type and play type during parent-infant play. Developmental Psychology, 33, 925-933.

Dumas, J. E. (1989). Treating antisocial behavior in children: Child and family approaches. Clinical Psychology Review, 9, 197-222.

Ehrlick, A., Gimpel, G. A., \& Veeder, M. A. (2004, November). Mothers' and fathers' interaction with their children. Poster session presented at the annual Association for Advancement of Behavior Therapy conference, New Orleans, LA.

Eisenstadt, T. H., Eyberg, S. M., McNeil, C. B., Newcomb, K., \& Funderburk, B. (1993). Parentchild interaction therapy with behavior problem children: Relative effectiveness of two stages and overall treatment outcome. Journal of Clinical Child Psychology, 22, 42-51.

Eisenstadt, T. H., McElreath, L. H., Eyberg, S. M., \& McNeil, C. B. (1994). Interparent agreement on the Eyberg Child Behavior Inventory. Child \& Family Behavior Therapy, $16,21-27$. 
Eyberg, S. M., Bessmer, J., Newcomb, K., Edwards, D., \& Robinson, E. (1994). Dyadic ParentChild Interaction Coding System-II: A manual. Social and Behavioral Sciences Documents (Ms. No. 2897). Retrieved February 4, 2005, from http://www.pcit.org

Eyberg, S. M., \& Calzada, E. J. (1998). Parent-Child Interaction Therapy: Procedures manual. Unpublished manuscript, University of Florida.

Eyberg, S. M., \& Pincus, D. (1999). Eyberg Child Behavior Inventory and Sutter-Eyberg Student Behavior Inventory: Professional Manual. Odessa, FL: Psychological Assessment Resources.

Eyberg, S. M., \& Robinson, E. A. (1982). Parent-child interaction training: Effects on family functioning. Journal of Clinical Child Psychology, 11, 130-137.

Eyberg, S. M., \& Robinson, E. A. (1983). Dyadic Parent-Child Interaction Coding System: A manual. Psychological Documents, 13, Ms. No. 2582.

Eyberg, S. M., \& Ross, A. W. (1978). Assessment of child behavior problems: The validation of a new inventory. Journal of Clinical Child Psychology, 7, 113-116.

Fagan, J., \& Iglesias, A. (1999). Father involvement program effects on fathers, father figures, and their head start children: A quasi-experimental study. Early Childhood Research Quarterly, 14, 243-269.

Forehand, R., \& McMahon, R. J. (1981). Helping the noncompliant child: A clinician's guide to parent training. New York: Spectrum.

Frentz, C., \& Kelley, M. L. (1986). Parents' acceptance of reductive treatment methods: The influence of problem severity and perception of child behavior. Behavior Therapy, 17, $75-81$. 
Frick, P. J., Christian, R. E., \& Wootton, J. M. (1999). Age trends in the association between parenting practices and conduct problems. Behavior Modification, 23, 106-128.

Friedemann, M. L., \& Andrews, M. (1990). Family support and child adjustment in single-parent families. Issues in Comprehensive Pediatric Nursing, 13, 289-301.

Funderburk, B. W., Eyberg, S. M., Rich, B. A., \& Behar, L. (2003). Further psychometric evaluation of the Eyberg and Behar rating scales of parents and teachers of preschoolers. Early Education and Development, 14, 67-81.

Furtkamp, E., Giffort, D., \& Schiers, W. (1982). In-class evaluation of behavior modification knowledge: Parallel tests for use in applied settings. Journal of Behavior Therapy \& Experimental Psychiatry, 13, 131-134.

Gage, J. D., \& Wilson, L. J. (2000). Acceptability of Attention-Deficit/Hyperactivity Disorder interventions: A comparison of parents. Journal of Attention Disorders, 4, 174-182.

Graziano, A. M.. \& Diament, D. M. (1992). Parent behavioral training: An examination of the paradigm. Behavior Modification, 16, 3-38.

Hembree-Kigin, T. L., \& McNeil, C. B. (1995). Parent-Child Interaction Therapy. New York: Plenum Press.

Herschell, A. D., McNeil, C. B., Urquiza, A. J., McGrath, J. M., Zebell, N. M. Timmer, S., et al. (2005). Evaluation of Two Strategies for Training Therapists in Parent-Child Interaction Therapy. Manuscript submitted for publication.

Hollingshead, A. B. (1957). Two factor index of social position. New Haven, CT: Yale University Press.

Jones, M. L., Eyberg, S. M., Adams, C. A., \& Boggs, S. R. (1998). Treatment acceptability of behavioral interventions for children: An assessment by mothers of children with 
disruptive behavior disorders. Child \& Family Behavior Therapy, 20, 15-26.

Kazdin, A. E. (1980a). Acceptability of alternative treatments for child deviant behavior. Journal of Applied Behavior Analysis, 13, 259-273.

Kazdin, A. E. (1980b). Acceptability of timeout from reinforcement procedures for disruptive child behaviors. Behavior Therapy, 11, 329-344.

Kazdin, A. E. (1981). Acceptability of child treatment techniques: The influence of treatment efficacy and adverse side effects. Behavior Therapy, 12, 493-506.

Kazdin, A. (1984). Acceptability of aversive procedures and medication as treatment alternatives for deviant child behavior. Journal of Abnormal Child Psychology, 12, 289-302.

Kazdin, A. E. (1987). Treatment of antisocial behavior in children: Current status and future directions. Psychological Bulletin, 102, 187-203.

Kazdin, A. E., \& Weisz, J. R. (1998). Identifying and developing empirically supported child and adolescent treatments. Journal of Consulting and Clinical Psychology, 66, 19-36.

Kazura, K. (2000). Fathers' qualitative and quantitative involvement: An investigation of attachment, play, and social interactions. Journal of Men's Studies, 9, 41-57.

Kelley, M. L., Heffer, R.H., Gresham, F.M., Elliot, S.N. (1989). Development of a modified treatment evaluation inventory. Journal of Psychopathology and Behavior Assessment, $11,235-247$.

Lamb, M. E. (1981). The development of father-infant relationships. In M. E. Lamb (Ed.), The role of the father in child development (pp.458-488). New York: Wiley.

Lamb, M. E. (1997). Fathers and child development: An introductory overview. In M. E. Lamb (Ed.), The role of fathers in child development (3rd ed., pp. 1-18). New York: Wiley. 
Leaper, C., Anderson, K. J., \& Sanders, P. (1998). Moderators of gender effects on parents' talk to their children: A meta-analysis. Developmental Psychology, 34, 3-27.

Levant, R. F., \& Doyle, G. F. (1983). An evaluation of a parent education program for fathers of school-aged children. Family Relations, 32, 29-37.

Levy-Shiff, R. (1982). The effects of father absence on young children in mother-headed families. Child Development, 53, 1400-1405.

Lewis, C. (1997). Fathers and preschoolers. In M. E. Lamb (Ed.), The role of the father in child development ( $3^{\text {rd }}$ edition; pp. 121-142). New York: Wiley.

MacDonald, K. B. (1988). Social and personality development: An evolutionary synthesis. New York: Plenum Press.

Marshall, D. B., English, D. J., \& Stewart, A. J. (2001). The effects of fathers or father figures on child behavioral problems in families referred to child protective services. Child Maltreatment: Journal of the American Professional Society on the Abuse of Children, 6, 290-299.

Marsiglio, W., Amato, P., \& Day, R. D. (2000). Scholarship on fatherhood in the 1990s and beyond. Journal of Marriage and the Family, 62, 1173-1191.

McBride, B. A. (1990). The effects of a parent education/play group program on father involvement in child rearing. Family Relations, 39, 250-256.

McBride, B. A., \& McBride, R. J. (1993). Parent education and support programs for fathers: Research guiding practice. Childhood Education, 70, 4-9.

McBride, B. A., \& Mills, G. (1993). A comparison of mother and father involvement with their preschool age children. Early Childhood Research Quarterly, 8, 457-477. 
McLoughlin, C. S. (1985). Utility and efficacy of knowledge of behavioral principles as applied to children. Psychological Reports, 56, 463-467.

McNeil, C. B., Eyberg, S. M., Eisenstadt, T. H., Newcomb, K., \& Funderburk, B. (1991). Parentchild interaction therapy with behavior problem children: Generalization of treatment effects to the school setting. Journal of Clinical Child Psychology, 20, 140-151.

Milkie, M. A., Bianchi, S. M., Mattingly, M. J., \& Robinson, J. P. (2002). Gendered division of childrearing: Ideals, realities, and the relationship to parental well-being. Sex Roles, 47, 21-38.

Miller, D. L., \& Kelley, M. L. (1992). Treatment acceptability: The effects of parent gender, marital adjustment, and child behavior. Child \& Family Behavior Therapy, 14, 11-23.

Miltenberger, R. G., Parrish, J. M., Rickert, V., \& Kohr, M. (1989). Assessing treatment acceptability with consumers of outpatient child behavior management services. Child \& Family Behavior Therapy, 11, 35-44.

Nixon, R. D. V., Sweeney, L., Erickson, D. B., \& Touyz, S. W. (2003). Parent-child interaction therapy: A comparison of standard and abbreviated treatments for oppositional defiant preschoolers.

O’Dell, S. L., Tarler-Benlolo, L., \& Flynn, J. M. (1979). An instrument to measure Knowledge of Behavioral Principles As Applied to Children. Journal of Behavior Therapy and Experimental Psychiatry, 10, 29-34.

Palkovitz, R. (1996). Parenting as a generator of adult development: Conceptual issues and implications. Journal of Social and Personal Relationships, 13, 571-592.

Parke, R. D., \& Brott, A. A. (1999). Throwaway dads: The myths and barriers that keep men 
from being the fathers they want to be. Boston: Houghton Mifflin Company.

Patterson, G. R. (1980). Mothers: The unacknowledged victims. Monographs of the Society for Research in Child Development, 45 (Serial No. 186).

Patterson, G. (1982). Coercive family process. Eugene, OR: Castalia.

Patterson, G. R., \& Dishion, T. J. (1988). Multilevel family process models: Traits, interactions, and relationships. In R. Hinde \& J. Stevenson (Eds.), Relationships with families: Mutual influences (pp. 283-310). Oxford, UK: Clarendon.

Pevsner, R. (1982). Group parent training versus individual family therapy: An outcome study. Journal of Behavior Therapy and Experimental Psychiatry, 13, 119-122.

Phares, V. (1992). Where's Poppa?: The relative lack of attention to the role of fathers in child and adolescent psychopathology. American Psychologist, 47, 656-664.

Pleck, J. H. (1997). Paternal involvement: Levels, sources, and consequences. In M. E. Lamb (Ed.), The role of the father in child development ( $3^{\text {rd }}$ edition; pp. 66-103). New York: Wiley.

Popenoe, D. (1999). Life without father: Compelling new evidence that fatherhood and marriage are indispensable for the good of children and society. Cambridge, MA: Harvard University Press.

Radin, N. (1986). The influence of fathers on their sons and daughters. Social Work in Education, 8, 77-91.

Robinson, E. A., \& Eyberg, S. M. (1981). The dyadic parent-child interaction coding system: Standardization and validation. Journal of Consulting and Clinical Psychology, 49, 245250. 
Rowe, M. L., Coker, D., \& Pan, B. A. (2004). A comparison of fathers' and mothers' talk to toddlers in low-income families. Social Development, 13, 278-291.

Russell, G., \& Russell, A. (1987). Mother-child and father-child relationships in middle childhood. Child Development, 58, 1573- 1585.

Sanders, M. R., \& Dadds, M. R. (1993). Behavioral family intervention. Needham Heights, MA: Allyn \& Bacon.

Serketich, W. J., \& Dumas, J. E. (1996). The effectiveness of behavioral training programs to modify antisocial behavior in children: A meta-analysis. Behavior Therapy, 27, 171-186.

Sheline, J. L., Skipper, B. J., \& Broadhead, E. (1994). Risk factors for violent behavior in elementary school boys: Have you hugged your child today? American Journal of Public Health, 48, 661-663.

Singh, N. N., \& Katz, R. C. (1985). On the modification of acceptability ratings for alternative child treatments. Behavior Modification, 9, 375-386.

Strain, P. S., Young, C. C., \& Horowitz, J. (1981). Generalized behavior change: During oppositional child training. Behavior Modification, 5, 15-26.

Stranger, C., \& Lewis, M. (1993). Agreement among parents, teachers, and children on internalizing and externalizing behavior problems. Journal of clinical Child Psychology, 22, $107-115$.

Strassberg, Z., Dodge, K. A., Pettit, G. S., \& Bates, J. E. (1994). Spanking in the home and children's subsequent aggression toward kindergarten peers. Development and Psychopathology, 6, 445-461.

Sturmey, P., Newton, T., Milne, D., \& Burdett, C. (1987). Parallel forms of the Knowledge of 
Behavioral Principles As Applied to Children Questionnaire: An independent, multicentered, British replication. Journal of Behavior Therapy and Experimental Psychiatry, $18,223-227$.

Tarnowski, K. J., Mulick, J. A., \& Rasnake, L. K. (1990). Acceptability of behavioral interventions for self-injurious behavior: Replication and interinstitutional comparison. American Journal on Mental Retardation, 95, 182-187.

Tiano, J. D., \& McNeil, C. B. (2005). The inclusion of fathers in behavioral parent training: A critical evaluation. Child \& Family Behavior Therapy, 27, 1-28.

Tingstrom, D. H. (1989). Increasing acceptability of alternative behavioral interventions through education. Psychology in the Schools, 26, 188-194.

United States Census Bureau. (2002). Census Bureau facts for features. Retrieved March 14, 2005, from http://www.census.gov/Press-Release/www/2003/cb03-97.html

Velez, C. N., Johnson, J., \& Cohen, P. (1989). A longitudinal analysis of selected risk factors for childhood psychopathology. Journal of the American Academy of Child and Adolescent Psychiatry, 28, 861-864.

Webster-Stratton, C. (1985a). The effects of father involvement in parent training for conduct problem children. Journal of Child Psychology and Psychiatry, 26, 801-810.

Webster-Stratton, C. (1985b). Mother perceptions and mother-child interactions: Comparison of clinic referred and nonclinic group. Journal of Clinical Child Psychology, 14, 334-339.

Webster-Stratton, C. (1985c). Predictors of treatment outcome in parent training for conduct disordered children. Behavior Therapy, 16, 223-243.

Webster-Stratton, C. (1988). Mothers' and fathers' perceptions of child deviance: Roles of parent 
and child behaviors and parent adjustment. Journal of Consulting and Clinical Psychology, 56, 909-915.

Webster-Stratton, C. (1990). Enhancing the effectiveness of self-administered videotape parent training for families with conduct-problem children. Journal of Abnormal Child Psychology, 18, 479-492.

Webster-Stratton, C. (1992). Individually administered videotape parent training: "Who benefits?" Cognitive Therapy and Research, 16, 31-35.

Webster-Stratton, C. (2000). Oppositional-defiant and conduct-disordered children. In M. Hersen \& R. T. Ammerman (Eds.), Advanced abnormal psychology (2nd ed., pp.387-412). Mahwah, NJ: Lawrence Erlbaum Associates, Inc.

Webster-Stratton, C., \& Hammond, M. (1990). Predictors of treatment outcome in parent training for families with conduct problem children. Behavior Therapy, 21, 319-337.

Webster-Stratton, C., \& Hammond, M. (1997). Treating children with early-onset conduct problems: A comparison of child and parent training interventions. Journal of Consulting and Clinical Psychology, 65, 93-109.

Weisz, J. R., Weiss, B., Han, S. S., Granger, D. A., \& Morton, T. (1995). Effects of psychotherapy with children and adolescents revisited: A meta-analysis of treatment outcome studies. Psychological Bulletin, 117, 450-468.

Wierson, M., \& Forehand, R. (1994). Parent behavioral training for child noncompliance: Rationale, concepts, and effectiveness. Current Directions in Psychological Science, 3, 146-150.

Witt, J. C., \& Robbins, J. R. (1985). Acceptability of reductive interventions for the control of 
inappropriate child behavior. Journal of Abnormal Child Psychology, 13, 59-67. 
Appendix A

\section{Demographic Information Questionnaire}

1. Parent age:

2. Parent gender (circle one):

Male Female

3. Parent race (circle one):

African American Non-white/Hispanic White/Caucasian Asian

American Indian Pacific Islander Bulacial

East Indian Other

4. What is your current marital status?

married- living together living together- not married

5. Total number of children in the home:

6. Ages of children:

5. Target child's age:

6. Child race (circle one):

African American Non-white/Hispanic White/Caucasian Asian

American Indian Pacific Islander Biracial $\quad$ Multiracial

East Indian Other

7. Highest amount of schooling you completed (circle one):

$>6^{\text {th }}$ grade Some College (no degree)

$6^{\text {th }}-8^{\text {th }}$ grade College Graduate (e.g., bachelor's degree)

$9^{\text {th }}-11^{\text {th }}$ grade Advanced Graduate Degree (e.g., master's degree)

High School Graduate

8. Annual household income: 
9. Do you work outside of the home?

If yes, are you currently (circle one):
working full-time

10. If full-time/part-time, how would you describe your occupation/job title (e.g., carpenter, teacher, etc)?

11. On average, how many hours in a typical weekday do you spend directly interacting with your child?

Of this time, how many hours are spent in care giving activities (e.g., feeding, bathing)?

How many of these hours per day are spent in play activities (e.g., reading a book, playing with toys, etc.)?

12. On average, how many hours in a typical weekend day do you spend directly interacting with your child?

Of this time, how many hours are spent in care giving activities (e.g., feeding, bathing)?

How many of these hours per day are spent in play activities (e.g., reading a book, playing with toys, etc.)? 
13a. What percent of the care giving activities for your child do you complete?

b. What percent of the care giving activities for your child does your partner complete?

(Note: $13 a$ and $13 b$ should add up to $100 \%$ )

14. How many hours per week is your child in the care of others (e.g., school, daycare, grandparent)?

15. If your child were exhibiting some problem behaviors and was referred to a psychologist/therapist, how likely would you be to take your child to the psychologist/therapist?

$\begin{array}{lllll}1 & 2 & 3 & 4 & 5\end{array}$

very unlikely somewhat unlikely neutral somewhat likely very likely

16. Why might you consider not taking your child to the psychologist/therapist?

17. Do you share caregiving responsibilities of your child with another person (other than your spouse/ partner)?

YES NO

If YES, please indicate who shares responsibility (check all that apply):

child's grandmother child's grandfather child's great grandmother child's great grandfather child's stepmother child's stepfather child's aunt child's uncle child's cousin child's older sibling other (please specify)

18. Are you the biological parent of the target child (circle one)?

YES

NO

19. How many years have you been involved in this child's life (e.g., living in the same house)? 
Appendix B

Eyberg Child Behavior Inventory 


\section{Appendix C}

\section{Case Description and Treatment Vignettes for TEI-SF}

\section{Directions}

Please read the following case description and treatment vignettes. Then answer items on the TEI-SF for each of the six vignettes (i.e., complete six total TEI-SF forms; one for each vignette).

Joe disobeys his parents a lot. He often refuses to do things his parents ask him to do, such as picking up his toys or doing other chores. When his parents ask him to put away his toys Joe often has a temper tantrum which includes yelling and throwing his toys. If anything breaks during a temper tantrum, he sometimes swears and he blames his parents. He argues with his parents a lot, especially when he doesn't get his own way. Joe also does things all the time to bother his younger sister, such as poking her over and over to make her cry. Joe also does things to his sister to make his parents mad. For example, the other day when his parents asked him to pour his sister's juice, Joe poured it on his sister. Every time Joe's parents try to talk to him about getting along with his sister, Joe acts touchy and annoyed.

1. To correct Joe's behavior, his parents ignore him when he disobeys, and give Joe lots of attention and praise every time Joe obeys. To ignore Joe, his parents do not say anything to him and act like they do not notice him. Whenever Joe does what his parents tell him to do, his parents tell him how much they like it, such as, "You did a good job of minding! Thank you for helping me."

2. To correct Joe's behavior, his parents practice following directions whenever he disobeys. For example, if Joe refuses to put his shirt in the hamper when told, his parents have Joe practice obeying by having him quickly put 10 articles of clothing in the hamper, one at a time. If needed, Joe's parents help him practice by, for example, guiding Joe to the hamper.

3. To correct Joe's behavior, his parents wait until after Joe disobeys and a while later again ask him to do the same or a different chore. Every time that Joe obeys, his parents put a sticker on Joe's sticker chart. When Joe earns four stars, his parents give him extra special things that he likes. The special things may be extra TV time, a special snack, a trip to the park to swing, or a small toy.

4. To correct Joe's behavior, his parents take away a privilege that Joe normally has, whenever Joe disobeys. Joe's parents tell Joe why he is losing the privilege for that day. The privileges that Joe might lose are things that he really likes, like a favorite TV show, dessert after dinner, a bedtime story, or playing with a favorite toy.

5. To correct Joe's behavior, his parents spank him whenever he disobeys. For example, if Joe refuses to put his shirt in the hamper, his parents walk Joe over to a chair and tell him because he didn't do what he was told, he is going to get a spanking. His parents then put Joe over their lap and give him two spanks on the bottom with the fingers of their hand.

6. To correct Joe's behavior, his parents have him sit in a chair in the corner whenever he disobeys. His parents have him sit on a chair for three minutes. After three minutes, Joe's parents will give him permission to get off the chair if he is quiet. If Joe gets off the chair before his parents give him permission, Joe must stay on the chair another three minutes. 


\section{Appendix D}

\section{Treatment Evaluation Inventory-Short Form (TEI-SF)}

\section{Directions}

Please complete each item below by circling the number next to each statement that best indicates how you feel about the treatment. Please read the items very carefully.

Please indicate which vignette number you are evaluating:

\begin{tabular}{|c|c|c|}
\hline $\begin{array}{l}\text { Strongly } \\
\text { Disagree }\end{array}$ & Disagree & Neutral \\
\hline
\end{tabular}

I find this treatment to be an acceptable way of dealing with the child's problem behavior

I'd be willing to use this procedure if I had to change the child's problem behavior

I believe that it would be acceptable to use this procedure without children's

I like the procedure used in this treatment

I believe this treatment is

I believe the child will experience discomfort during

I believe the treatment is likely to result in permanent

I believe it would be acceptable to use this treatment with individuals who cannot choose treatments for themselves 


\section{Appendix E}

\section{KNOWLEDGE OF BEHAVIORAL PRINCIPLES AS APPLIED TO CHILDREN}

\section{Directions}

Please read each question and each of its four possible answers. Sometimes more than one answer could be correct under certain circumstances; however, you should select the best answer or the answer that is most generally true. Completely circle the letter beside the answer.

\section{Example:}

Probably the most important influence in a young child's life is his
a. toys
b. television
c. parents
d. friends

Please do not consult others while deciding how to answer the question. Be sure to answer every question even if you must guess.

1. Desirable and undesirable behavior are most alike in that they are
a. the result of emotions and feelings.
b. habits and therefore difficult to change.
c. ways the child expresses himself.
d. the result of learning.

2. Most problem behavior in young children is probably
a. a reaction to deeper emotional problems.
b. due to lack of communication in the home.
c. accidentally taught by the child's family.
d. due to a stage which the child will outgrow.

3. Which of the following is most important for parents in controlling their child's behavior?
a. the rules the parents make about behavior.
b. the parents' understanding of the child's feelings.
c. the behaviors to which the parents attend.
d. being strict, but also warm and gentle.

4. Which of the following is the least likely way for children to react to the person who punishes them?
a. the child will try to avoid the punisher.
b. the child will have admiration and respect for the punisher.
c. the child may copy the punisher's methods and do similar things to playmates.
d. the child will associate punishment with the punisher. 
5. If you are trying to teach a child to talk, you should first:

a. reward the child after speaking a sentence.

b. reward the child for saying a word.

c. reward the child for any vocalization.

d. punish the child if he does not speak.

6. A child has been rewarded each time he cleans his room. In order to keep the room clean without having to use a reward, the next step should probably be to:

a. have a talk about how pleased you are and then stop giving the reward.

b. give the reward about one out of five times.

c. give the reward almost every time.

d. You must always reward it every time.

7. When should a child who is just learning to dress himself be praise the first time?

a. When he gets his foot through the first hole in his underwear.

b. When he gets his underwear completely on.

c. When he asks to do it himself.

d. When he has completely dressed himself.

8. Three of the following responses refer to terms of punishment which are mild and effective. Which one is not?

a. Ignoring the undesirable behavior.

b. Sending the child to a dull room for a few minutes.

c. Taking away something the child likes (such as dessert after supper).

d. Scolding.

9. Which of the following is the most effective form of punishment in the long run for reducing a child's undesirable behavior?

a. Scolding him every time he does it.

b. Occasionally spanking him when he does it.

c. Sending him to his room for five minutes every time he does it.

d. Sending him to his room all afternoon every time he does it.

10. A good rule to remember is:

a. Do not reward with money if possible.

b. Catch a child doing something right.

c. Reward good behavior and always punish bad behavior.

d. Punishment is always unnecessary.

11. Which of the following is true about punishment?

a. Punishment teaches respect.

b. Punishment should be delayed until it can be carefully determined that it is really necessary.

c. Punishment can teach a child new behaviors.

d. Some punishments can result in a child becoming aggressive. 
12. A boy loves football. What is most likely to happen if, each time he is playing nicely with his sister, his father invites him to play football?

a. He will always be asking his father to play football.

b. He will play nicely with his sister more often.

c. He will be annoyed with his father for interfering with his activities.

d. He will be encouraged to teach his sister to play football.

13. A father is teaching his son to hit a thrown ball with a bat. Which of the following methods will probably most help his son learn to hit?

a. Let him try to hit the ball without saying anything, so the child can learn on his own.

b. Occasionally tell him what he is doing wrong.

c. Occasionally tell him what he is doing right.

d. Tell him almost every time he does something right.

14. Punishment, as a way to get rid of undesirable behavior, is best used when:

a. you are very upset.

b. you want to teach the child the right way to behave.

c. the behavior may be dangerous.

d. scolding does not seem effective.

15. If you want your child to develop proper study habits, you should:

a. encourage him to do his homework.

b. help him to see school as pleasant.

c. reward him whenever he studies.

d. give him good reasons why he will need school.

16. A child often cries over any small matter that bothers him. How should his parents react to best reduce his crying?

a. Reward when he reacts without crying.

b. Use a mild punishment when he cries.

c. Try to find out what is really troubling the child and deal with that.

d. Provide him with something interesting so he will stop crying.

17. If you want your child to say "please" and "thank you" at the table, it probably is most important to:

a. reprimand him when he forgets to say them.

b. explain why good manners are important.

c. remember to compliment him when he remembers to say them.

d. praise other members of the family when they use these words. 
18. A major problem has been getting Leon to bed in the evening. His mother has decided to change this and wants to measure relevant behaviors. Which is the best way for her to do this?

a. Each evening record whether or not he goes to bed on time.

b. Chart his behavior all day long, up to and including bedtime to try to find out what causes his not wanting to go to bed.

c. Each week, make a note of how easy or difficult it has been to get him to bed.

d. Ask Leon to keep his own record each week.

19. A father tells a child he cannot go to the store with him because the child didn't clean his room like he promised. The child reacts by shouting, crying, and promising he will clean the room when he gets home. What should the father do?

a. Ignore the child and go to the store.

b. Take him to the store, but make him clean his room when they return.

c. Calm him down and go help him clean his room together.

d. Talk to him and find out why he doesn't take responsibility.

20. In changing a behavior it is most important to use:

a. methods which have been tested by others.

b. consequences which are rewarding to the child.

c. consequences which are punitive to the child.

d. rewards which do not bribe the child.

21. Stan is doing a number of things that greatly disturb his parents. It would be best for them to:

a. try to quickly eliminate all of these undesirable behaviors at once.

b. select just a few behaviors to deal with at first.

c. select the single behavior they find the most disruptive and concentrate on changing that.

d. wait for 28 to 30 days before beginning to try to change his behaviors to make sure they are stable and persistent.

22. Listed below are four methods to change behavior. Which is usually the best technique to get Frank to stop sucking his thumb?

a. Punish the undesirable behavior.

b. Ignore the behavior.

c. Reward him for desirable behavior in the situation in which he usually sucks his thumb.

d. Explain to Frank why the behavior is undesirable.

23. If you want to make a behavior a long-lasting habit, you should:

a. reward it every time.

b. first reward it every time and then reward it occasionally.

c. Promise something the child wants very much.

d. Give several reasons why it is important and remind the child of the reasons often. 
24. The most likely reason a child misbehaves is because:

a. he is expressing angry feelings which he often holds inside.

b. he has learned to misbehave.

c. he has not been properly told that his behavior is wrong.

25. A baby often screams for several minutes and gets his parent's attention. Which of the following is probably the best way for his parents to reduce the screaming?

a. If there is nothing physically wrong with the child, ignore his screaming even though the first few times he screams even louder.

b. Distract the child with something he finds interesting whenever he screams.

c. Ignore all the noises and sounds the child makes.

d. None of the above. Babies usually have good reasons for screaming.

\section{KEY}

1. D

2. $\mathrm{C}$

3. $\mathrm{C}$

4. B

5. $\mathrm{C}$
6. C

7. A

8. D

9. $\mathrm{C}$

10. B
11. D

12. B

13. D

14. C

15. C
16. A

17. C

18. A

19. A

20. B
21. C

22. $\mathrm{C}$

23. B

24. B

25. A 


\section{Appendix F \\ Instructions for Observations of 3 Standard Situations}

\section{CDI}

Please tell your child that he may play with whatever he chooses. Let him choose any activity he wishes. Just follow his lead and play along with him.

\section{PDI}

Now please tell your child that it is your turn to choose the activity. You may choose any activity you wish. Keep him playing with you according to your rules.

\section{$\mathbf{C U}$}

Now please tell your child that it is time to clean up the toys. Make sure you have him put the toys away by himself. Have him put all the toys in their containers and the containers lined up on the table. 


\section{Appendix G \\ DPICS-II CODING SHEET}

Date:

Subject \#:

Parent Gender:
Observer Name:

Parent:

Situation: o CDI o PDI o CU

\begin{tabular}{|c|l|l|l|}
\hline PARENT BEHAVIOR & TOTAL & CHILD BEHAVIOR & TOTAL \\
\hline Labeled Praise (LP) & & Compliance & \\
\hline Unlabeled Praise (UP) & & Smart Talk (ST) & \\
\hline Information Description (ID) & & Critical Statement (CR) & \\
\hline Behavioral Description (BD) & & Destructive (DS) & \\
\hline Reflection (RF) & & Yell (YE) & \\
\hline $\begin{array}{l}\text { Positive Behavior } \\
\text { (LP+UP+RF+Descriptions) }\end{array}$ & & Whine (WH) & \\
\hline Question & & Negative Beh. \\
(ST+CR+DS+YE+WH)
\end{tabular}




\section{Appendix $\mathrm{H}$}

\section{DPICS-II Definitions}

\begin{tabular}{|l|l|}
\hline \multicolumn{1}{|c|}{ Parent Behavior } & \multicolumn{1}{|c|}{ Definition } \\
\hline Positive Behavior & $\begin{array}{l}\text { Positive behaviors include labeled praise, unlabeled } \\
\text { praise, reflections, behavioral descriptions, and } \\
\text { information descriptions. }\end{array}$ \\
\hline Aversive Behavior & $\begin{array}{l}\text { Aversive behaviors include criticisms and smart } \\
\text { talk. }\end{array}$ \\
\hline Controlling Behavior & $\begin{array}{l}\text { Controlling behaviors include direct and indirect } \\
\text { commands. }\end{array}$ \\
\hline Other & $\begin{array}{l}\text { Other behaviors include verbalizations that are not } \\
\text { included in the coded categories. }\end{array}$ \\
\hline Amount of Interaction & $\begin{array}{l}\text { Amount of interaction includes all comprehensible } \\
\text { parental verbalizations }\end{array}$ \\
\hline \multicolumn{1}{|c|}{ Child Behavior } & Definition \\
\hline Compliance & $\begin{array}{l}\text { Obeying or beginning to obey the command within } \\
5 \text { seconds. } \\
\text { behaviors, yell, and whine. }\end{array}$ \\
\hline Eybers, destructive \\
\hline sehavior
\end{tabular}

Eyberg, Bessmer, Newcomb, Edwards, \& Robinson. (1994). Dyadic Parent-Child Interaction Coding System-II: A manual. Retrieved February 4, 2005, from http://www.pcit.org 
Table 1

Demographic Characteristics of Entire Sample

\begin{tabular}{lcc}
\hline Demographic variable & $M$ & $S D$ \\
\hline Parent age $^{\mathrm{a}}$ & 34.24 & 6.40 \\
Child age $^{\mathrm{b}}$ & 4.65 & 1.65 \\
Number of children in the home $^{\mathrm{a}}$ & 2.28 & .81 \\
Involvement with child $^{\mathrm{a}}$ & 14.62 & 6.41 \\
Number of hours per week child is in care of others $^{\mathrm{a}}$ & 24.55 & 15.65 \\
Additional individuals sharing caregiving activities $^{\mathrm{a}}$ & 2.03 & 1.31 \\
Hollingshead Index $^{\mathrm{a}}$ & 2.56 & \\
& $($ upper middle class) & \\
ECBI Intensity scale raw score $^{\mathrm{c}}$ & 103.38 & 20.19 \\
ECBI Problem scale raw score $^{\mathrm{c}}$ & 6.52 & 5.42 \\
\hline
\end{tabular}

Parent race

Caucasian

79

$98.75 \%$

African American

1

$1.25 \%$

Child race

Caucasian

39

$97.50 \%$

Biracial

1

$2.50 \%$

Marital Status

Married

76

$95.00 \%$

Not married

4

$5.00 \%$

Biological parent

76

$95.00 \%$

Note. ECBI $=$ Eyberg Child Behavior Inventory (Eyberg \& Pincus, 1999).

a represents $n=80 .{ }^{\mathrm{b}}$ represents $n=40{ }^{\mathrm{c}}$ represents $n=79$. 
Table 2

Demographic Characteristics of Sample Based on Gender

\begin{tabular}{|c|c|c|c|}
\hline \multirow[b]{2}{*}{ Demographic Variable } & \multirow{2}{*}{$\begin{array}{l}\text { Mother } \\
M(S D)\end{array}$} & \multicolumn{2}{|l|}{ Father } \\
\hline & & $M(S D)$ & $t$ \\
\hline Age & $32.43(5.87)^{\mathrm{a}}$ & $36.05(1.02)^{\mathrm{a}}$ & $-5.858 * * *$ \\
\hline Involvement with child & $16.89(5.93)^{\mathrm{a}}$ & $12.35(6.12)^{\mathrm{a}}$ & $-3.688 * *$ \\
\hline ECBI Intensity Scale raw score & $104.85(21.48)^{\mathrm{a}}$ & $101.87(18.94)^{b}$ & .581 \\
\hline \multirow[t]{3}{*}{ ECBI Problem Scale raw score } & $5.95(5.89)^{\mathrm{a}}$ & $7.10(4.90)^{b}$ & -1.112 \\
\hline & Mother & Father & \\
\hline & $M(S D)$ & $M(S D)$ & $\chi^{2}$ \\
\hline Hollingshead Index & $2.70(1.22)^{\mathrm{a}}$ & $2.43(.93)^{\mathrm{a}}$ & 19.543 \\
\hline
\end{tabular}


Table 3

Follow-up of Paired Samples T tests of TEI-SF Acceptability Scores

\begin{tabular}{lcccc}
\hline & $\begin{array}{c}\text { Mother } \\
(n=40)\end{array}$ & $\begin{array}{c}\text { Father } \\
(n=40)\end{array}$ & & \\
\cline { 2 - 4 } TEI-SF vignette & $M(S D)$ & $M(S D)$ & $t(39)$ & $d$ \\
\hline Differential Attention & $25.70(7.60)$ & $25.00(5.75)$ & .528 & .008 \\
Overcorrection & $27.58(7.29)$ & $28.89(8.14)$ & -.862 & -.14 \\
Positive Reinf. & $29.78(7.13)$ & $31.03(5.96)$ & -.883 & -.14 \\
Response Cost & $35.83(3.76)$ & $33.53(4.81)$ & $2.498^{*}$ & .40 \\
Spanking & $20.63(7.01)$ & $25.75(7.23)$ & $-4.191 * * *$ & -.66 \\
Timeout & $32.88(5.68)$ & $31.83(6.91)$ & .908 & .14 \\
\hline
\end{tabular}

$* \mathrm{p}<.05 .{ }^{* * *} \mathrm{p}<.001$. 
Table 4

Follow-up Paired Samples T Tests of Observed Behavior Composites

\begin{tabular}{|c|c|c|c|c|}
\hline & $\begin{array}{l}\text { Mother } \\
(n=40)\end{array}$ & $\begin{array}{l}\text { Father } \\
(n=40)\end{array}$ & & \\
\hline Composite & $M(S D)$ & $M(S D)$ & $t(39)$ & $d$ \\
\hline Parent Positive Behavior & $57.23(32.61)$ & $46.13(24.25)$ & $2.674 *$ & .42 \\
\hline Parent Aversive Behavior & $3.58(4.60)$ & $4.60(4.60)$ & -1.183 & -.19 \\
\hline Parent Controlling Behavior & $43.40(30.82)$ & $40.23(26.69)$ & .833 & .13 \\
\hline Child Percent Compliance & $.27(.18)$ & $.26(.17)$ & .398 & .05 \\
\hline Child Negative Behavior & $3.68(6.31)$ & $6.00(10.91)$ & -1.684 & -.27 \\
\hline Labeled Praise Statements & $.78(1.25)$ & $.55(1.08)$ & 1.120 & .16 \\
\hline Total Verbalizations & $163.03(80.84)$ & $148.15(68.21)$ & 1.602 & .25 \\
\hline
\end{tabular}

$* \mathrm{p}<.05$ 
Table 5

Intercorrelations Between Father Involvement and Paternal Variables

\begin{tabular}{|c|c|c|c|c|c|c|c|c|c|c|c|c|c|c|}
\hline & 1 & 2 & 3 & 4 & 5 & 6 & 7 & 8 & 9 & 10 & 11 & 12 & 13 & 14 \\
\hline 1. Involvement & - & .160 & -.085 & .075 & -.132 & .115 & $.316^{*}$ & -.055 & -.226 & -.050 & .166 & .262 & -.123 & $.396^{*}$ \\
\hline 2. ECBI Intensity Scale* & & - & -.174 & $.338^{*}$ & .238 & .003 & -.021 & -.023 & -.039 & .017 & -.229 & .108 & .015 & .076 \\
\hline 3. KBPAC & & & - & .224 & -.302 & -.139 & .025 & -.265 & -.124 & .201 & -.041 & -.163 & -.046 & .231 \\
\hline 4. TEI-SF Differential Attention & & & & - & .151 & .145 & .146 & -.074 & -.061 & .038 & -.151 & .037 & .017 & .300 \\
\hline 5. TEI-SF Overcorrection & & & & & - & .081 & .253 & .184 & $.377^{*}$ & -.170 & -.192 & .256 & .227 & -.106 \\
\hline 6. TEI-SF Positive Reinf. & & & & & & - & .213 & -.033 & .118 & .202 & .007 & $.338^{*}$ & .002 & .254 \\
\hline 7. TEI-SF Response Cost & & & & & & & - & .269 & $.348^{*}$ & -.070 & .076 & .307 & -.046 & .151 \\
\hline 8. TEI-SF Spanking & & & & & & & & - & $.413^{* *}$ & -.138 & -.042 & .088 & -.084 & -.174 \\
\hline 9. TEI-SF Timeout & & & & & & & & & - & -.216 & -.072 & .149 & .032 & .004 \\
\hline 10. Positive Beh. Composite & & & & & & & & & & - & $.370^{*}$ & $.541^{* *}$ & -.098 & .106 \\
\hline 11. Aversive Beh. Composite & & & & & & & & & & & - & $.442^{* *}$ & -.087 & $.393^{*}$ \\
\hline 12. Controlling Beh. Composite & & & & & & & & & & & & - & -.094 & .303 \\
\hline 13. Percent Child Compliance & & & & & & & & & & & & & - & -.185 \\
\hline 14. Child Neg. Beh. Composite & & & & & & & & & & & & & & - \\
\hline
\end{tabular}

Note. ECBI = Eyberg Child Behavior Inventory (Eyberg \& Pincus, 1999). KBPAC = Knowledge of Behavioral Principles as Applied To Children (Furtkamp, Giffort, \& Schiers, 1982). TEI-SF = Treatment Evaluation Inventory - Short Form (Kelley, Heffer, Gresham, \& Elliott, 1989). Reinf. $=$ Reinforcement and Beh.

$=$ Behavior.

$\mathrm{n}=40$, except $*$ represents $\mathrm{n}=39$

${ }^{*} \mathrm{p}<.05 .{ }^{* *} \mathrm{p}<.01$. 
Table 6

Intercorrelations Between Demographic Variables and Treatment Acceptability and Knowledge of Behavioral Principles

\begin{tabular}{|c|c|c|c|c|c|c|c|c|c|c|c|c|c|c|}
\hline & 1 & 2 & 3 & 4 & 5 & 6 & 7 & 8 & 9 & 10 & 11 & 12 & 13 & 14 \\
\hline 1. Parent Gender & - & $-.285^{*}$ & $.356 * *$ & .127 & .000 & .074 & -.107 & .053 & -.085 & -.096 & $.260^{*}$ & $-.341 * *$ & .084 & .106 \\
\hline 2. Parent Age & & - & -.220 & $-.277^{*}$ & $.267^{*}$ & -.112 & .018 & .099 & -.172 & -.021 & $-.269 *$ & -.011 & $-.256^{*}$ & $.381 * *$ \\
\hline 3. Involvement & & & - & .182 & $-.366^{* *}$ & .155 & .133 & .105 & -.143 & .140 & $.289 *$ & $-.277^{*}$ & -.012 & .002 \\
\hline 4. Hollingshead Index & & & & - & .012 & .215 & .171 & .033 & .178 & .002 & .138 & .136 & .074 & $-.262 *$ \\
\hline 5. Child Age & & & & & - & $-.246^{*}$ & -.047 & -.009 & -.101 & -.106 & $-.248 *$ & -.176 & .018 & $.325 * *$ \\
\hline 6. ECBI Intensity Scale* & & & & & & - & $.548 * *$ & .046 & .209 & .123 & .065 & .089 & .056 & $-.313 * *$ \\
\hline 7. ECBI Problem Scale* & & & & & & & - & .056 & .216 & .101 & -.053 & -.004 & .103 & -.126 \\
\hline 8. TEI-SF Diff. Attn. & & & & & & & & - & .166 & $.255^{*}$ & .142 & -.105 & .063 & .180 \\
\hline 9. TEI-SF Overcorrection & & & & & & & & & - & .027 & $.235^{*}$ & .086 & $.339 * *$ & -.170 \\
\hline 10. TEI-SF Positive Rein. & & & & & & & & & & - & .056 & -.013 & .120 & -.124 \\
\hline 11. TEI-SF Resp. Cost & & & & & & & & & & & - & .089 & $.382 * *$ & -.037 \\
\hline 12. TEI-SF Spanking & & & & & & & & & & & & - & .081 & $-.273 *$ \\
\hline 13. TEI-SF Timeout & & & & & & & & & & & & & 一 & -.115 \\
\hline 14. KBPAC & & & & & & & & & & & & & & - \\
\hline
\end{tabular}

Note. $\mathrm{n}=80$, except $*$ represents $\mathrm{n}=79 . \mathrm{ECBI}=$ Eyberg Child Behavior Inventory (Eyberg \& Pincus, 1999). TEI-SF $=$ Treatment Evaluation Inventory - Short Form (Kelley, Heffer, Gresham, \& Elliott, 1989), Diff. Attn. = Differential Attention, Rein. $=$ Reinforcement, Resp. $=$ Response, and KBPAC $=$ Knowledge of Behavioral Principles as Applied To Children (Furtkamp, Giffort, \& Schiers, 1982).

$* p<.05 .{ }^{*} p<.01$. 
Table 7

Intercorrelations Between Demographic Variables and Observed Behaviors and Knowledge of Behavioral Principles

\begin{tabular}{|c|c|c|c|c|c|c|c|c|c|c|c|c|c|}
\hline & 1 & 2 & 3 & 4 & 5 & 6 & 7 & 8 & 9 & 10 & 11 & 12 & 13 \\
\hline 1. Parent Gender & - & $-.285^{*}$ & $.356 * *$ & .127 & .000 & .074 & -.107 & .192 & -.112 & .056 & .027 & -.131 & .106 \\
\hline 2. Parent Age & & - & -.220 & $-.277^{*}$ & $.267 *$ & -.112 & .018 & .136 & .125 & -.128 & .007 & .108 & $.381 *$ \\
\hline 3. Involvement & & & - & .182 & $-.366^{* *}$ & .155 & .133 & .150 & .131 & .217 & -.037 & $.245^{*}$ & .002 \\
\hline 4. Hollingshead Index & & & & - & .012 & .215 & .171 & -.134 & .061 & .082 & -.036 & .060 & $-.262 *$ \\
\hline 5. Child Age & & & & & - & $-.246^{*}$ & -.047 & -.217 & -.167 & $-.546 * *$ & .151 & $-.303 * *$ & $.325^{* *}$ \\
\hline 6. ECBI Intensity Scale ${ }^{a}$ & & & & & & - & $.548 * *$ & .021 & -.112 & $.229 *$ & -.026 & .080 & $-.313 * *$ \\
\hline 7. ECBI Problem Scale ${ }^{a}$ & & & & & & & - & -.037 & .158 & .166 & -.152 & .171 & -.126 \\
\hline 8. Positive Beh. Comp. & & & & & & & & - & $.305^{*}$ & $.456 * *$ & -.065 & .115 & .118 \\
\hline 9. Aversive Beh. Comp. & & & & & & & & & - & $.346^{* *}$ & -.079 & $.388^{* *}$ & .039 \\
\hline 10. Controlling Beh. Comp. & & & & & & & & & & - & -.151 & $.226^{*}$ & $-.227^{*}$ \\
\hline 11. Child \% Compliance ${ }^{b}$ & & & & & & & & & & & - & -.090 & .005 \\
\hline 12. Child Neg Beh. Comp. & & & & & & & & & & & & - & .088 \\
\hline 13. KBPAC & & & & & & & & & & & & & - \\
\hline
\end{tabular}

Note. $\mathrm{n}=80$, except ${ }^{\mathrm{a}}$ represents $\mathrm{n}=79$ and ${ }^{\mathrm{b}}$ represents $\mathrm{n}=70 . \mathrm{ECBI}=$ Eyberg Child Behavior Inventory (Eyberg \& Pincus, 1999). KBPAC $=$ Knowledge of Behavioral Principles As Applied To Children (Furtkamp, Giffort, \& Schiers, 1982). Beh. = Behavior and Neg $=$ Negative.

$* \mathrm{p}<.05 . * *_{\mathrm{p}}<.01$. 